\title{
LONG-TERM PERFORMANCE ASSESSMENT OF AN OPERATIVE POST-TENSIONED TIMBER FRAME STRUCTURE
}

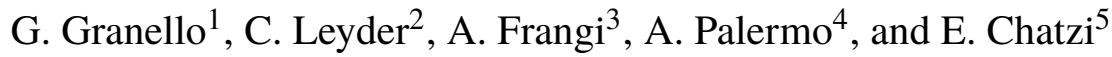 \\ ${ }^{1} \mathrm{PhD}$, Lecturer, University of Canterbury, Civil and Natural Resources Engineering. Email: \\ gabriele.granello@canterbury.ac.nz \\ ${ }^{2} \mathrm{PhD}$, Post doctoral fellow, ETH Zürich, Institute of Structural Engineering. \\ ${ }^{3} \mathrm{PhD}$, Professor, ETH Zürich, Institute of Structural Engineering. \\ ${ }^{1} \mathrm{PhD}$, Professor, University of Canterbury, Civil and Natural Resources Engineering \\ ${ }^{5} \mathrm{PhD}$, Associate Professor, ETH Zürich, Institute of Structural Engineering.
}

\section{ABSTRACT}

The concept of post-tensioned timber structures has been developed and implemented since 2005. The technology relies on un-bonded post-tensioned timber elements to create a momentresisting connection. After several years of extensive experimental testing, the first buildings were constructed from 2010. Although comprehensive research has been conducted on their behaviour under static and dynamic loading, limited data is available about their long-term performance. In particular, there is limited understanding of how to estimate the long-term post-tensioning losses. This paper presents two years of experimental observations on a fully monitored post-tensioned timber building: the House of Natural Resources. Additionally, a numerical approach based on a moisture-dependent visco-elastic model is presented to simulate the post-tensioning trend over time.

\section{INTRODUCTION}

Post-tensioned timber frames were first proposed at the University of Canterbury in 2005 (Palermo et al. 2005) and known as "PresLam". The construction technique takes advantage of 
un-bonded post-tensioned steel tendons passing through internal ducts in timber box beams, frames or walls, to create a moment-resisting connection (Buchanan et al. 2008). The seismic demand is accommodated through dissipative, controlled rocking motion between the structural elements. The tendon elongation enables a re-centring capability, while mild steel or other types of energydissipation devices can provide supplemental energy dissipation, if necessary (Sarti et al. 2017). This construction technique, called a "hybrid connection", draws its roots from concrete applications developed during the PREcast Seismic Structural Systems (PRESSS) program coordinated by the University of California San Diego (Priestley 1991). In 2002 the concept was extended to steel structures (Christopoulos et al. 2002) and later transferred to engineered timber products (Palermo et al. 2005). Due to the high degree of prefabrication and the potential of rapid assembly on site, the PresLam system may further prove to be a valuable construction technique for structures such as gravity frames (van Beerschoten et al. 2012), making the technology a valid alternative for low seismic risk areas as well. Post-tensioned pure timber connections have been studied at the ETH Institute of Structural Engineering since 2010. The system developed in Switzerland (Wanninger 2015), termed "Flexframe", differs from that adopted in New Zealand in the implementation of hardwood reinforcement (ash wood) in the beam-column joint. The use of hardwood, loaded perpendicular to the grain, obviates the need for further steel fasteners in the column, which are otherwise necessary to protect the timber.

It is well known that the long-term behaviour of timber may strongly deviate from its short-term behaviour. Long-term rheological effects, such as creep, mechano-sorptive creep and relaxation, commonly occur. Creep of wood materials depends on the permanent loads applied (Morlier 2004) and therefore, in post-tensioned timber frames, it significantly depends upon the tendon force. When creep deformations take place, the post-tensioning force is consequently reduced due to shortening of the timber section. The phenomenon is therefore a mixture of creep (increase in deformation in the timber elements under constant stress) and stress relaxation (decrease in stress under constant deformation), since neither the stress nor the deformation is constant over time . Therefore, it is assumed that the effect of creep in timber is more significant than the stress relaxation in the tendon 
by several orders of magnitude. In the following paper, the mixture of these two phenomena will be referred to as creep, since creep in the timber elements needs to occur before the tendon force can drop.

An initial series of tests on the long-term behaviour of post-tensioned glued laminated timber (glulam) beam and frame specimens was carried out at ETH Zürich in both a controlled and an uncontrolled environment (Wanninger et al. 2014). These tests enabled a first prediction for the long-term losses. The experimental results were, in fact, used within the analytical model developed by Fragiacomo and Davies 2011, which indicated a post-tensioning loss equal to ca. $30 \%$ in 50 years. This result was utilized to determine the initial post-tensioning force for the House of Natural Resources (HoNR) (see section 2).

Post-tensioned Laminated Veneer Lumber (LVL) frame specimens (Davies and Fragiacomo 2011) and beams (Granello et al. 2017) were monitored under controlled and uncontrolled environmental conditions, allowing the identification of the parameters most influencing the response, namely moisture content variations and the angle between the post-tensioning force and the timber grain. The first relationship occurs because under constant environmental conditions wood behaves as a viscoelastic material (Ranta-Maunus 1975). Changes in relative humidity produce a variation in timber moisture content. This variation affects the strength capacity of the timber (e.g., Palka 1973; Feldborg and Johansen 1988), its durability (e.g., Leicester 2001; Van de Kuilen 2007) and increases the rate of creep deformation (e.g.,Armstrong and Kingston 1960; Kingston and Clarke 1961; Lu and Leicester 1997). This last effect is also known as mechano-sorptive creep.

As creep development perpendicular to the grain is much higher than in the direction parallel to the grain (Morlier 2004), a post-tensioned frame, where the columns are loaded perpendicular to their fibre orientations, exhibits greater losses than an equivalent beam loaded parallel to the grain. For this reason, in practical post-tensioned frame applications (e.g. Brown et al. 2012) timber is not loaded directly perpendicular to the grain, and often, internal or external steel plates or rotated LVL panels are employed for constructing the beam-column detail.

In terms of post-tensioning loss prediction, an analytical model was proposed by Fragiacomo 
and Davies 2011 to estimate the losses in post-tensioned beams and frames. This model was later modified and extended by Giorgini et al. 2010, including diverse tendon profiles. However, both these formulations require knowledge of the variation in moisture content in the timber members during their service life, which may be difficult to obtain.

While the body of research completed is significant, limited information is available regarding the long-term performance of post-tensioned timber systems under operative conditions. In particular, the quantification of post-tensioning losses derived from creep (pure and mechano-sorptive) phenomena arising in the compressed members is still under investigation. So far, only results from small-scale tests under laboratory conditions are available, and extensive data from post-tensioned timber elements implemented in an actual timber building are still missing.

The main contribution of this paper to the current body of research, is the presentation of recent monitoring data from an operative post-tensioned timber building (Leyder et al. 2015b), named the House of Natural Resources (HoNR) and the application of a numerical model to simulate its post-tension losses. As the HoNR is a fully instrumented research building, significant timeseries information is available, allowing a better correlation between post-tensioning losses and environmental conditions, as well as insights about the magnitude of the rheological phenomena. Furthermore, it represents a real-case application (as a research and regular office building), with the real environmental conditions a building is subjected to from the construction phase through to the operation phase.

This paper is organized in two main sections. First, the experimental data acquired in the HoNR will be presented (climate data, moisture content and post-tension forces). In the second part, a modelling approach based on a well-known moisture dependent visco-elastic constitutive law is presented and compared with the experimental data.

\section{EXPERIMENTAL RESULTS}

\section{Overview of the House of Natural Resources}

The HoNR is the first post-tensioned timber building in Switzerland, located at the Campus Hönggerberg of ETH Zürich (cf. figure 1). In Switzerland, hardwood is a widely available resource, 
which is rarely implemented, however, in timber constructions (Krackler et al. 2011). The frames of the HoNR show the implementation of hardwood in the columns, making the HoNR the first post-tensioned timber frame building without any steel reinforcement in the beam-column joint.

The building is not only a living research lab, but further serves as an office building for the laboratory of hydraulics, hydrology and glaciology of ETH Zürich (VAW), thus facilitating research and monitoring under service conditions.

The structure is a four-storey building, with the two lower storeys featuring conventional reinforced concrete construction, while the two upper storeys constructed of timber. The two upper storeys, will be referred to as C-storey (first storey with post-tensioned timber frame) and D-storey (second storey with post-tensioned timber frame). The building was designed according to the Swiss SIA codes (SIA260) for office use with a live load and the seismic zone of Zürich (zone 1 with $a_{g d}=0.6 \mathrm{~m} / \mathrm{s}^{2}$ ). The first-storey floor system is a timber-concrete composite floor developed at ETH Zürich (Boccadoro 2016). The floor section is made of a beech LVL plate and a concrete plate, mechanically connected via rectangular shear notches in the timber plate. On the second storey, two different floor systems were implemented. The first is a hollow-core timber-concrete composite floor system, with a lower beech LVL plate and an upper prefabricated concrete plate, connected via beech LVL posts. For the central span $(6.5 \mathrm{~m} \times 6.5 \mathrm{~m})$, a pure timber floor was implemented. Further details and drawings of the structural systems implemented in the HoNR can be found in (Leyder et al. 2015b).

In what follows, the focus is on the post-tensioned timber frame, whose long-term behaviour is discussed in this paper.

\section{Post-tensioned timber frame}

The main structural system is a two-storey post-tensioned timber frame made of ash glulam columns and hybrid ash-spruce glulam beams (14 spruce lamellae (upper part) and 4 ash lamellae (lower part)). The timber elements were installed without any special surface treatment. The frame is designed to carry both gravity and horizontal loads. Eight three-bay frames of $6.5 \mathrm{~m}$ span constitute the building, with four frames running along one direction, and four frames in the 
perpendicular direction (cf. figures 2,4).

The connection between the columns and beams is achieved via an un-bonded post-tensioned straight tendon running through the entire length of each frame (in both directions). The position of the cables is roughly at the mid-height of the beam, whereas the position of the cables in one direction is shifted slightly below mid-height and the position of the cables in the other direction slightly above mid-height ( $\pm 3.5 \mathrm{~cm}$ eccentricity). The columns are running through the entire room height.

The beam-column joint was developed at ETH Zürich via several series of tests, ranging from small-scale laboratory tests to full-scale pushover tests. Details about the development, tests and long-term behaviour are documented in Wanninger 2015 and Wanninger et al. 2014. The design of the building frame was based on these preliminary tests. The columns feature cross-sections of $380 \mathrm{~mm} \times 380 \mathrm{~mm}$, whereas the beams are $280 \mathrm{~mm}$ wide and $720 \mathrm{~mm}$ high. The heights of the columns are $2.64 \mathrm{~m}$ (bottom connection axis to central axis of the post-tension cable). The timber and tendon properties are summarized in Tables 1 (SIA265; DIN EN338) and 2, (Stahlton AG). The tendons were initially post-tensioned to roughly $700 \mathrm{kN}$, which corresponds to a stress level of about 3.5MPa in the timber section. The level of initial post-tensioning force accounts for the $30 \%$ losses expected to occur over a design life of 50 years. This prediction was originally made by extrapolating the results obtained by Wanninger et al. 2014. The detailing of the tendon anchorage was realized in such a way that the tendons could be externally re-stressed in case large losses should occur.

The post-tensioned timber frame is the only horizontal load-carrying structure. The nonstructural elements (staircase and façade) are structurally disconnected from the frame. All interior walls are non-structural walls made of gypsum plasterboard. The two-storey frame is connected to the two lower concrete storeys via a steel plate with glued-in rods (connection concrete-steel) and a dowel type connection (connection steel-timber). For the structural design, this connection was considered as a pinned connection. The first-storey column is connected to the second-storey column via glued-in rods in both columns, each fixed to a steel plate. The two steel plates are 
welded together. This connection was considered as a rigid connection for the design of the frame. Figures of the connection details can be found in Leyder et al. 2015b.

\section{Construction process}

The construction of the first-storey post-tensioned timber frame was carried out in January 2014. After the mounting of the frame, the construction site was protected with a plastic cover against weathering. In March 2014 the first-storey floor was added. The construction of the second-storey post-tensioned timber frame was carried out in July 2014, followed by the addition of the second-storey floor in October 2014. In December 2014, the underlay floors were cast and the façade was installed.

The building is equipped with floor heating, whose regular operation started in February 2015; however, the building does not feature an automated air conditioning or ventilation system. Windows inside the glass façade can be opened by the users and allow for inflow of fresh air, so the users can significantly influence the indoor climate. Furthermore, the user can control the amount of sunlight entering the rooms by operating the shading system. On 2 June 2015 the building was inaugurated, and the occupants moved in during July 2015.

In what follows, three main environmental-condition phases will be distinguished: firstly, the construction phase (January 2014-October 2014); secondly, a transition phase (November 2014May 2015); and thirdly, the operational phase (June 2015-June 2016). The transition phase covers the period in which the main structural elements are already finalized, while the climate is gradually changing from outdoor conditions to indoor conditions (mounting of the façade, activation of heating). The end of the transition phase is defined with the start of the building occupancy, since the building users play an important role in the regulation of the indoor climate.

\section{Monitoring setup and resulting data}

To gain valuable information regarding the new technologies implemented in this structure, the building is instrumented with a dense sensor network (Leyder et al. 2015a). Monitoring was initiated during the construction phase and is still continuing to gather information on the short- and long-term performance of all these innovative structural systems. Early results of this monitoring 
system have been presented in Leyder et al. 2015a, in which extended results are reported upon, including one full year of the operation phase (monitoring data until June 2016). As this paper focuses specifically on the long-term behaviour of the post-tensioned timber frame, only results from the indoor climate sensors (referred to as $\mathrm{T} \& \mathrm{RH}$ for temperature and relative humidity sensors), the moisture content measurements and the load cell measurements will be presented. The temperature, relative humidity and load cell sensors are connected to a data acquisition unit, where 5-min averages are continuously logged. The moisture content measurement is manually performed and is conducted every 2 weeks (operation phase).

Table 3 presents an overview of the different monitoring systems and their operation phase.

\section{Temperature and relative humidity $(T \& R H)$}

Climate conditions significantly influence the moisture content of timber and its mechanical properties (Morlier 2004), and have therefore been monitored since the beginning of the construction phase.

During the construction phase, the building was instrumented with a single climate station, placed in a central location (cf. figure 4a). This setup assumes that the climate is approximately constant throughout the construction site, since the internal walls and/or the façade do not hinder the airflow. During the transition phase (in February 2015), 12 combined sensors, measuring temperature and relative humidity were installed in 12 different rooms and are still in operation. The indoor climate is controlled by the user (opening of windows/activation of shading), and therefore the "local" climate may vary from room to room.

Figure 5 presents the daily average of temperature and relative humidity. The black line represents a single value in the construction phase and the beginning of the transition phase (recorded by the climate station) and then the average between the 12 values (recorded by the 12 distributed sensors). The grey lines represent the 12 individual values. Temperature and relative humidity indicate a clear transition of the climate from outdoor to indoor conditions. While the outdoor phase is characterized by large cycles (temperature between $0{ }^{\circ} \mathrm{C}$ and $30^{\circ} \mathrm{C}$ and relative humidity between $30 \%$ and $70 \%$ ), the indoor phase corresponds to lower amplitude 
cycles (temperature between $20^{\circ} \mathrm{C}$ and $30^{\circ} \mathrm{C}$ and relative humidity between $35 \%$ and $55 \%$ ). These ranges of humidity and temperature inside the building are consistent with what is expected for building in Service Class 1, as outlined in Eurocode 5 Part 1-1 Section 2.3.1.3 (Comité Européen de Normalisation).

\section{Moisture content of timber}

The moisture content of timber strongly influences its mechanical properties and therefore delivers an important contribution to the evolution of the post-tensioning losses. The moisture content in the timber is measured via its electrical resistance, via insulated steel needles, which are drilled into the timber. A total of 41 moisture content sensors (1 sensor comprises a pair of insulated steel needles) were implemented along the timber frames at a depth of $6 \mathrm{~cm}$ (measurement at the tip of the needle) (cf. figure 3). In the hybrid beams, the measurement points were installed in the ash and spruce wood, designated E for ash (from the German "Esche") and F for spruce (from the German "Fichte") (cf. figure 4). The measurement points are positioned on the side of the beam and columns, facing the façade. The measurements for the two different materials did not show a significant difference in the variation of their moisture content, and are therefore not further distinguished .

Figure 6 indicates the moisture content measurements for both storeys. The black line indicates the mean value. The moisture content at production for both storeys was around 10 to $11 \%$ (indication by the producer). It is unclear why the moisture content measured initially is significantly larger than the values at production for the C-storey. The timber elements for the C-storey frame were delivered to the construction site in early December 2013 (wrapped in thin plastic foil, no protecting roof yet installed). The erection was, however, delayed until January, due to the operational temperature of the adhesive used for the glued-in rods to fix the column bases to the concrete. During this period a significant increase of moisture content might have occurred. It can be noted that the moisture content measurement indicates a large spatial variation. During the construction phase, measurements were extracted at instants distributed irregularly over time . During the operation phase, measurements were obtained regularly every 2 weeks, leading to 
a higher temporal consistency in the data points. Additionally, there is a noticeable difference between the initial moisture content of the first-storey frame, erected in the wintertime and the second-storey frame erected during the summer, which might be explained as being due to its exposure to a significantly different outdoor climate. During the transition phase, the building went through its first heating period, with a low level of ventilation, since ventilation requires building occupants to open the windows. This might explain why this period exhibits the lowest moisture content values in the entire data series.

Moisture content measurements often exhibit marked variability, as discussed in Forsén and Tarvainen 2000. Indicated accuracies of the electrical resistance method are commonly in the range of $\pm 1 \%$ moisture content. The measured values should therefore be considered carefully and serve rather as an indication of a trend, than as absolute values.

\section{Tendon forces}

At the anchorage of each of the 16 tendons, one load cell is installed, which continually records the post-tensioning force in each frame. Figure $3 \mathrm{c}$ displays a picture from the installation process of the load cell. The load cell is mounted between the tendon anchorage and the load distribution steel plate fixed to the timber column. The load cells were installed prior to the post-tensioning process of the frame. All tendons were post-tensioned to about $700 \mathrm{kN}$.

Figure 7 presents the evaluation of the post-tension load from January 2014 to June 2016. The initial post-tensioning force was $700 \mathrm{kN}$ for both storeys. The first-storey load cells were installed in January 2014 and a calibration was performed in March 2014 (as can be seen from the second drop in figure 7). The load cells on the second storey were added in July 2014.

In June 2016, the maximum decrease in tendon force corresponds to $90 \%$ of the initial load. The first storey load cell data show a consistent drop from January 2014 until June 2014. Then, a stabilization phase occurs, followed by another drop starting in February 2015, and stabilizing again in February 2016. On the second storey, a different behaviour is observed. First, the tendon loads increase until October 2014, then a constant decrease occurs until June 2016, which eventually appears to converge to a flat plateau in the operational phase. One explanation for this difference 
in behaviour might be the different environmental conditions during the erection (winter/summer) and the different initial moisture contents. Furthermore, there might be an influence of the vertical load on the frame. The first-storey floor is a massive timber-concrete composite floor, leading to significant vertical loads on the post-tensioned timber frame, whereas the second-storey floor is significantly lighter.

Table 4 and figure 7 compare the post-tension losses in the HoNR to the measured and extrapolated post-tension losses from the small-scale laboratory specimens in the uncontrolled environment ((Wanninger 2015) p.103). As rheological processes in timber are time-varying and depend on many external factors, the extrapolation to 50 years presents high uncertainties and should therefore be considered as a rough indication only. In the laboratory test, different specimen sizes were tested, with beam dimensions of 1050 $120 \cdot 240 \mathrm{~mm}$ (length·width·depth) and column dimensions of $600 \cdot 120 \cdot 100 / 160 / 240 \mathrm{~mm}$ (length·width·depth) (cf. figure 15 in the appendix and Wanninger 2015). For the laboratory tests, the contribution of pure creep and mechano-sorptive creep could be separately analysed, because measurements were conducted in a controlled environment (constant temperature and relative humidity). This separation is obviously no longer possible for the posttensioning data obtained from the building, due to the uncontrolled climate conditions. Another main difference is that no increase in post-tension force is recorded on the $\mathrm{C}$-storey. The increasing post-tension phase is replaced by a flat plateau in the building's data. Indeed, the vertical loads might hinder this increase in post-tensioning load from winter to summer. Furthermore, the seasonal cycles in the post-tension force are more significant for the laboratory data, which may be explained by the smaller cross-sections. For the D-storey, the seasonal effects are clearly out of phase. Indeed the laboratory tests were post-tensioned at the beginning of October 2012, whereas the C-storey frame was post-tensioned in January and the D-storey frame in July, so there is a seasonal delay of 9 months for the D-storey. Unfortunately, no laboratory specimens were post-tensioned in summer, so the influence of the environment at post-tensioning can only be seen from the HoNR data for the D-storey. Table 4 indicates that after one year, the losses in the building results were significantly lower than those observed for the laboratory specimens (despite the missing "increasing phase"). 
This difference is mainly due to the different geometrical properties of the systems. As outlined by (Fragiacomo and Davies 2011), the ratio between the post-tensioning area and the cross-section of the timber element strongly affects the amount of post-tensioning loss. Because post-tensioning losses occur essentially due to an imposed displacement by the tendon force, the higher the ratio between post-tensioning area and total area of the timber member, the higher the post-tensioning losses.

Additionally, the correlations between the measured environmental conditions (temperature and relative humidity) and the tendon forces were calculated. The linear correlation factor between temperature and tendon force is -0.7 and +0.6 for relative humidity and tendon force (for both storeys). This indicates that an increase in temperature leads to a decrease in post-tension force, and an increase in relative humidity leads to an increase in post-tension force (positive correlation factor). Both temperature and relative humidity seem to have a similarly strong influence. The influence of the temperature might be explained via the following physical phenomenon: An increase in temperature leads to an elongation of the steel tendon between the anchorage points, which results in a decrease in the post-tension load. The positive correlation between relative humidity and post-tension force may be explained via a swelling of the timber sections, pushing against the tendon anchorage and therefore leading to an increase in the tendon force.

In the following sections, a physical model will be applied to simulate the interaction between environmental conditions and post-tensioning force.

\section{NUMERICAL MODELLING APPROACH}

\section{Scope and limitations}

Modelling the long-term behaviour of timber is a rather complex task, which involves two main challenges:

1. the simulation of the moisture transfer between the material and the environment;

2. the definition of a proper constitutive law.

The mechanics of moisture transfer in wood is still an object of research. The most advanced 
models rely on non-Fickian approaches (Wadsö 1994; Krabbenhoft and Damkilde 2004) or multiFickian (Frandsen et al. 2007). Their formulation is rather complex and requires the definition of several material parameters.

Fickian models, although representing a simplification of the problem, are probably the most used (Fortino et al. 2009; Khorsandnia et al. 2015; Hassani et al. 2015). They rely on two main assumptions (Krabbenhoft and Damkilde 2004): 1) the moisture flux is described by a Fickiantype gradient law, and 2) the water in the boundary cells is at all times in equilibrium with the surrounding mixture of vapour and air.

When elements have a dominant dimension with respect to the others, as in the case of beams, simplified approaches were adopted in the modelling (Toratti 1992; Fragiacomo 2005; Schänzlin 2010; Khorsandnia et al. 2015). Specifically, the moisture content over the member's cross section is computed by assuming it to be constant over the length of the member. Although this last approach strongly simplifies the moisture content transfer phenomenon, it allows an indication of the average moisture content of timber beams subjected to variable environmental conditions. Furthermore, it require fewer parameters to be defined for the material.

Regarding the visco-elastic behaviour of wood, it presents strongly non-linear characteristics. As outlined by Schaffer 1972:

"Wood behaves non-linearly over the whole stress-level range, with linear behaviour being a good approximation at low stresses. Because of this nearly linear response at low level of stress, Boltzmann's superposition principle applies to stress-strain behaviour for stresses up to $40 \%$ of short time behaviour".

The most recent constitutive laws (Hassani et al. 2015) are able to include non-linearities in the material's stress-strain relationship, such as plasticity. Such constitutive laws are rather complex to define and implement, and, above all, require several material parameters to describe a specific wood product.

If the applied stress is small enough, a valid alternative is represented by linear visco-elastic constitutive laws (e.g. Toratti 1992; Mårtensson 1994; Hanhijarvi 1995). These have the advantage 
of being easier to implement, and they require fewer material parameters in defining a wood species. Furthermore, because the problem becomes linear, the solution can be calculated by using Boltzman's superposition principle, which significantly reduces the computational effort. Because no previous numerical model has been attempted until now to describe the long-term behaviour of post-tensioned timber frame structures, the simplest modelling approach, i.e. based on moisture transfer computation for beams and visco-elastic constitutive law (similar to the one performed by (Toratti 1992; Fragiacomo 2005; Schänzlin 2010; Khorsandnia et al. 2015)), is implemented here. Another justification for this approach depends on the limited number of parameters necessary to describe, although in a simplified manner, the wood material. Despite more advanced material models (for example Krabbenhoft and Damkilde 2004; Hassani et al. 2015) being recommended for future applications to improve the quality of the simulations, their application to the HoNR with the available experimental data is not currently feasible. Because such constitutive laws are more detailed and made of a greater number of material parameters, they require more experimental data in order to be properly calibrated. For example, a more refined moisture profile within the timber elements and more than a single measurement in one location needs to be available to properly calibrate the moisture transfer properties. Because of the lack of experimental information, the option of a simpler modelling approach was chosen.

Another complexity in attempting the modelling of the structure, regardless of the constitutive law adopted, is represented by the uncertainty existing over the humidity demand, for which data are missing for some periods (see Figure 6). If the conditions suddenly varied drastically in those periods, the consequent sharp variation of the moisture content would increase the amount of mechano-sorption. While higher control over the data quality can be achieved in a laboratory experiment during short periods of time, the monitoring of a real structure, especially over years, represents a much greater challenge. However, it is believed that monitoring can offer a better representation of the reality when compared with a laboratory specimen, and therefore it is worthwhile to present and investigate the case. Although the numerical approach to such a complex case study may not be acknowledged as fundamental, it is likely that it can offer further elements for better 
interpreting the monitored data.

\section{Overview of the modelling approach}

The proposed procedure subdivides the time domain into finite intervals, considering the tendon force as constant within the time step: by fixing the load at the beginning of the time step, visc-oelastic displacements can be evaluated. At the end of the time step, the evaluated deformation is utilized to compute the new value of the post-tensioning force by imposing displacement compatibility at the anchorage interface. This new force value is then the starting point for the subsequent time step. As creep depends on both the variation of moisture content and stress, the modelling approach should combine both factors. This can be achieved by coupling a diffusion analysis with a visco-elastic analysis, as firstly proposed by Toratti 1992. The first operation computes the moisture distribution within the timber element and the second one calculates the creep deformation based on the stress and the average moisture content.

An overview of the procedure is presented in Figure 8. Four main sub-procedures can be identified within the same time step, in particular: a) problem definition, b) diffusion analysis, c) visco-elastic analysis, and d) post-tensioning updating.

\section{Problem definition}

The first sub-procedure (Figure 8) initializes the finite element model that will be used to simulate the mechanical behaviour. The timber member is modelled by using finite beam elements with fibre section formulation (Taucer et al. 1991). Geometrical variables such as beam length, section dimensions, and kinematic boundary conditions are defined. Post-tensioning is taken into account as an equivalent load system and is therefore considered either as a set of point loads or distributed loads, depending on the tendon profile, that is, straight, draped, or parabolic (Naaman 1982). Since post-tensioning is dependent on time, its initial value is manually assigned at the first iteration, but is automatically updated at the end of each time step. 


\section{Diffusion analysis}

The variation of moisture content over time for a timber section can be expressed according to Equation 1 with respect to Figure 9:

$$
\frac{\partial u}{\partial t}=D_{y} \frac{\partial^{2} u}{\partial^{2} y^{2}}+D_{z} \frac{\partial^{2} u}{\partial^{2} z^{2}}
$$

where $D_{y}$ and $D_{z}$ are the diffusion coefficients along $y$ and $z$ directions respectively.

Boundary conditions are set in terms of flux equilibrium between the section board and the environment, according to Equation 2:

$$
q_{y}=S_{y}\left(u_{R H}-u_{\text {surface }}\right)
$$

$$
q_{z}=S_{z}\left(u_{R H}-u_{\text {surface }}\right)
$$

where $q_{y}$ and $q_{z}$ represent the humidity flux along $y$ and $z$, respectively; $S_{y}$ and $S_{z}$ represent the surface emissivity and $u_{\text {surface }}$ the moisture content along the section perimeter. The term $u_{R H}$ expresses the timber moisture content in equilibrium with the environmental conditions, which is a function of the environmental humidity and the temperature, according to Equation 3 (Rasmussen 1961):

$$
u_{R H, T}=\frac{1800}{W}\left[\frac{k h}{1-k h} \frac{k_{1} k h+2 k_{1} k_{2} k^{2} h^{2}}{1+k_{1} k h+k_{1} k_{2} k^{2} h^{2}}\right]
$$

with $W, k, k_{1}, k_{2}$ being parameters of the model dependent on the environmental temperature $T$ and relative humidity $h$. Their values are obtained from the Equation set 4:

$$
\begin{aligned}
W & =330+0.452 T+0.00415 T^{2} \\
k & =0.791+4.63 \cdot 10^{-4} T-8.44 \cdot 10^{-7} T^{2} \\
k_{1} & =6.34+7.75 \cdot 10^{-4} T-9.35 \cdot 10^{-5} T^{2} \\
k_{2} & =1.9+2.84 \cdot 10^{-2} T-9.04 \cdot 10^{-5} T^{2}
\end{aligned}
$$

Equation 1 can be solved numerically through a finite difference (FD) integration procedure by discretizing the cross section. To further reduce the material parameters, as done by other authors 
(Toratti 1992; Fragiacomo 2005; Schänzlin 2010; Khorsandnia et al. 2015), the following equalities are imposed $S_{z}=S_{y}=S$ and $D_{z}=D_{y}=D$.

Visco-elastic analysis

According to Toratti 1992 and Svensson and Toratti 2002, the stress-strain relationship can be written in the following integral form:

$$
\begin{aligned}
& \epsilon(t)=\underbrace{\int_{t_{0}}^{t} J_{0}(u(\tau)) \frac{\partial \sigma(\tau)}{\partial \tau} \partial \tau+\int_{t_{0}}^{t} \sigma(\tau) \frac{\partial J_{0}(u(\tau))}{\partial u(\tau)} \partial u(\tau)}_{\text {Elastic strain }}+\underbrace{\int_{t_{0}}^{t} J_{c}(t, \tau) \frac{\partial \sigma}{\partial \tau} \partial \tau}_{\text {Creep strain }} \\
& +\underbrace{J^{\infty} \int_{t_{0}}^{t}\left(1-e^{-c \int_{\tau}^{t}\left|d u\left(\tau_{1}\right)\right|}\right) \frac{\partial \sigma(\tau)}{\partial \tau} \partial \tau}+\underbrace{\int_{t_{0}}^{t} m_{m s} \sigma(\tau)|U(\tau)| d \tau} \\
& \text { Mechano-sorptive strain recoverable Mechano-sorptive strainirrecoverable } \\
& \underbrace{-\int_{t_{0}}^{t} b \epsilon(\tau) d u(\tau)}_{\text {Shrinkage/swelling strain }}+\underbrace{\int_{t_{0}}^{t} \alpha_{u} d u(\tau)}_{\text {Inelastic strain }}
\end{aligned}
$$

where $\epsilon, J, \sigma, u, t_{0}, t$ and $\tau$ are respectively the total strain, creep compliance, total stress, moisture content, initial time, final time and current time of the analysis. The term $U$ refers to moisture levels not reached during the previous stress history. The model parameters that depend on material properties are $c, J^{\infty}, m_{m s}$ and $\alpha_{u}$. The creep function $J(t, \tau, u)$ is defined according to Toratti 1992 as:

$$
J(t, \tau, u)=J_{0}(u)+J_{c}(t, \tau)=\frac{1}{E_{0}\left(1-k_{u} u\right)}+\frac{1}{E_{0}\left(1-k_{u} u_{r e f}\right)}\left(\frac{t-\tau}{t_{d}}\right)^{m}
$$

where $E_{0}$ is the elastic modulus of dried timber, $u_{r e f}$ the reference moisture content, $k_{u}$ the model parameter, $t_{d}$ and $m$ the material properties. The creep function can be expanded as the sum of $\mathrm{N}$ Kelvin chains and written as:

$$
J(t, \tau, u)=J_{0}(u)+\sum_{n=1}^{N} J_{n}\left(1-e^{-(t-\tau) / \tau_{n}}\right)
$$

Equation 5 can be numerically integrated by subdividing the time domain in finite steps of amplitude $\Delta t$ and considering a constant stress within the interval (Khorsandnia et al. 2015). 


\section{Post-tensioning updating}

The fourth sub-procedure aims to update the post-tensioning force for the subsequent time step with the known timber displacements. The post-tensioning force, at $t+\Delta t$, can be computed as shown in Equation 8:

$$
P^{t+\Delta t}=P^{t}+\Delta P_{\text {comp }}^{t+\Delta t}+\Delta P_{\text {therm }}^{t+\Delta t}
$$

where $\Delta P_{\text {comp }}^{t+\Delta t}$ represents the force variation due to anchorage compatibility, and $\Delta P_{t h e r m}^{t+\Delta t}$ the force variation due to the thermal inelastic deformation of tendons.

Timber displacements at the anchorage are assumed to be equal to (except for their sign) the displacements corresponding to the tendons. Therefore, if $\Delta d_{t e n}^{t}$ is the timber displacement variation corresponding to the anchorage, $-\Delta d_{t e n}^{t}$ is the displacement variation occurring in the post-tensioned steel. The negative sign underlines that for a shortening occurring in the cable, a post-tensioning loss is expected.

Neglecting steel relaxation and considering an elastic stress-strain constitutive law for steel, the variation of post-tensioning force can be computed as:

$$
\Delta P_{\text {comp }}^{t+\Delta t}=-\frac{\Delta d_{t e n}^{t}}{L_{t e n}} E_{S} A_{s}
$$

where $L_{t e n}$ is the tendon's length, $A_{s}$ and $E_{s}$ are the post-tensioning steel area and elastic modulus, respectively.

The calibration of the model parameters to the data of the laboratory specimens from Wanninger 2015 can be found in the appendix of this paper.

\section{Model Application to the HoNR}

\section{Environmental conditions and moisture content}

In the following section, the proposed numerical model is applied to simulate the post-tension losses in the HoNR. The relative humidity and temperature implemented in the simulation have already been presented in figure 5. The simulation is based on average temperature and relative humidity values (over 12 sensors), as the differences between the rooms and the C- and D-storey 
are not significant (maximum difference of $5^{\circ} \mathrm{C}, 15 \%$ ).

The comparison between simulated and measured moisture content in beams and columns is illustrated in figures 10 and 11.

Overall the model captures the moisture content trend over time with sufficient accuracy. Starting from April 2015, there is a constant shift between the simulation and the measurements, where the simulation predicts consistently lower values of moisture content. The measured moisture content in the timber elements is on average equal to $10 \%$, while average relative humidity and temperatures are around $30-50 \%$ and $20-30^{\circ} \mathrm{C}$, respectively (cf. figure 5). The simulation implements Rasmussen's formula (Rasmussen 1961) according to which the equilibrium moisture content for this environmental conditions should be around 7.5-8.5\%. It is unclear whether the elements have already fully reached the equilibrium moisture content, as the cross sections are quite large. Furthermore, Rasmussen's formula was based on averages over several wood species, and therefore the comparison with spruce and ash moisture measurement data may present some differences.

Further reasons for the differences between the simulation and the measurements might be the following:

- During the first part of the transition phase there is only one sensor measuring the relative humidity and temperature, which is considered representative of the climate of the entire building during the simulation. This assumption may not be completely justified and therefore some differences may occur. In the operation phase, 12 sensors are operative, but the variation between different rooms is low, justifying a calculation with a single average value. During the construction phase, however, this variation was unknown and might have been be significantly larger.

- During the transition phase, the building was covered by a plastic membrane to protect the timber elements from rain. However, the moisture content sensors are placed along the outer perimeter of the frame where the timber members are more exposed to the environment (side wind and rain due to limited tightness of the membrane from the side). The relative 
humidity measured at the centre of the building might therefore not be representative for the climatic condition along the perimeter of the frame.

- The accuracy of the moisture content measurement device is indicated as $\pm 1 \%$ moisture content by the producers.

- The moisture transfer is modelled through a simplified approach. More refined procedures, e.g., (Wadsö 1994; Krabbenhoft and Damkilde 2004; Frandsen et al. 2007), may provide better accuracy.

These uncertainties about the moisture content are also likely to influence the post-tensioning trend.

Post-Tensioning Trend

The post-tensioning trend is illustrated in figure 12. For the C-storey, the model starts from March 2014, after the re-tensioning of the cables (calibration). The simulation on the second storey presents a good agreement with the experimental results. The average error of the tendon force is $0.39 \%$. The simulation of the first storey presents a greater error, especially from December 2014 to September 2015. The average error is $2.5 \%$. Reasons for this significant difference between the C- and the D-storey data fit might be as follows:

- The uncertainty in the moisture content explained in the previous section is reflected in the post-tensioning trend. Since the simulated moisture content is decreasing in the transition phase, a drop in the post-tensioning loss is obtained. However, the recorded moisture content does not show this drop and consequently the measured post-tensioning force does not rapidly decrease. This leads to a transient error in the PT loss simulation, which has already completely disappeared for the D-storey data, but not completely for the C-storey data.

- Another source of inaccuracy is represented by the post-tensioning application time in the simulated results. As the load cells on the lower storey were calibrated in March 2014, the post-tensioning force was simulated starting from March 2014 (continuous data series). However the tendons were already stressed in January 2014, and the period between January 
2014 and March 2014 is neglected in the simulation. This is not expected to have extreme consequences for the long-term simulation accuracy; it may lead to some uncertainties at the beginning of the simulation.

Despite these uncertainties, the model is capable of describing the trend with sufficient accuracy. The developed model allows an analysis of the different contributions to the post-tensioning loss (cf. figure 13). When comparing the contribution of the beams (spruce loaded parallel to the grain) and the columns (ash loaded perpendicular to the grain), the columns clearly present the highest contribution (over $50 \%$ of the total loss); the beams only contribute a small part. The significant difference between the temperature during the construction and the operation phase leads to a significant contribution in the thermal expansion of the post-tensioning cable. This contribution will, however, diminish in the future, since the building's indoor temperature has a significantly lower variation in the operation phase.

\section{CONCLUSIONS}

This paper presents the experimental climate, moisture content and post-tension data from the first post-tensioned timber frame building in Switzerland and the first post-tensioned timber building with columns in hardwood world-wide. Additionally, a numerical model was calibrated based on laboratory small-scale tests and then applied to simulate the phenomenon of post-tension losses from the construction phase until the first year of the operation phase.

Concerning the experimental data of the first two years (construction, transition and operation), the main findings can be summarized as follows:

- The post-tension losses in the HoNR building are on average around 7\% in 2-2.5 years. A maximum scatter of about $\pm 3 \%$ in terms of post-tensioning losses can be observed between the load cells with respect to the average.

- The climatic conditions changed significantly from the construction phase to the operation phase. In particular, the seasonal variations were drastically reduced for the operation phase. This is likely to influence the further development of the post-tensioning loss trend. 
- The initial moisture content of the timber elements is fairly high (around 14\%) and then stabilizes at around 10 to $12 \%$ in the operation phase

- The linear correlation factors between the environmental data and the post-tensioning force demonstrate that there is likely a strong influence on the post-tension losses from the environmental conditions.

- The post-tension losses were largest during the construction and transition phase. It can be expected that the decay rate of post-tension force will further reduce in the future, since the climate in the operation phase is significantly more stable.

From the modelling point of view, a numerical approach to simulate the post-tensioning trend has been presented. Although the formulation relies on simplified assumptions, it allows the capture of the system properties with reasonable accuracy at the macroscopic level (cf. average moisture content and post-tensioning trend over time).

The simulation captures the trend of the moisture content, although the accuracy in absolute value is limited. Differences around $\pm 1-2 \%$ can be observed between the experimental data and the numerical results. These discrepancies can be due to both the simplified numerical approach and the limited accuracy of moisture content measurements in timber.

In terms of the post-tensioning forces, the model is able to follow the trend with reasonable precision. Although the model is based on a simplified approach, it can be utilized to analyse the main contributing factors to the post-tensioning loss.

The two main contributors were identified as follows:

- The contribution of the columns accounts for roughly $50 \%$ of the total loss in the first two years. This is a direct consequence of the creep function: timber loaded perpendicular to the grain presents a significantly higher creep factor than timber loaded parallel to the grain.

- The contribution of thermal strains in the post-tension cable is quite significant. This component may have a significant influence when the stressing operations are carried out in particularly cold environments (e.g. in winter) and the building is then heated up to $20^{\circ} \mathrm{C}$ 
for the operation phase.

Further research is necessary on the modelling side, for example by applying more refined material models, to increase the accuracy of the simulations.

The results presented were based on a two-year time frame. A longer period of observation is necessary to have more reliable information on the moisture content trend, as well as the evolution in the post-tensioning loss. It should be noted also that protecting the structure from adverse weather, as was the case for the House of Natural Resources, may not represent typical construction practice. In the case of an unprotected structure, the post-tensioning loss could be magnified by higher moisture uptakes in the timber members due to the increase of mechano-sorptive creep effects.

Further data regarding the building will therefore be collected in the following months to provide further information on the long-term performance of post-tensioned timber structures.

\section{ACKNOWLEDGEMENTS}

The authors gratefully acknowledge the financial support of the ETH Foundation, Climate-KIC and the Structural Timber Innovation Company (STIC).

\section{REFERENCES}

Armstrong, L. D. and Kingston, R. S. T. (1960). "Effect of moisture changes on creep in wood." Nature, 185(4716), 862-863.

Boccadoro, L. (2016). "Timber-concrete composite slabs made of beech laminated veneer lumber with notched connection." Ph.D. thesis, Eidgenössische Technische Hochschule ETH Zürich, Nr. 23577.

Brown, A., Lester, J., Pampanin, S., and Pietra, D. (2012). "Preslam in practice - a damage-limiting rebuild project." SESOC Conference, Auckland.

Buchanan, A., Deam, B., Fragiacomo, M., Pampanin, S., and Palermo, A. (2008). "Multi-storey prestressed timber buildings in new zealand." Structural Engineering International: Journal of the International Association for Bridge and Structural Engineering (IABSE), 18(2), 166-173. 
Christopoulos, C., Filiatrault, A., Uang, C., and Folz, B. (2002). "Post-tensioned energy dissipating connections for moment resisting steel frames." Journal of Structural Engineering, 128(9), $1111-1120$.

Comité Européen de Normalisation (2004). "Eurocode 5: Design of timber structures. part1-1: General rules and rules for buildings." ENV 1995-1-1.

Davies, M. and Fragiacomo, M. (2011). "Long-term behavior of prestressed LVL members. i: Experimental tests." Journal of Structural Engineering, 137(12), 1553-1561.

DIN EN338 (2010). “Structural timber-strengt classes; German version EN DIN Deutsches Institut für Normung." V., Berlin, Germany.

Feldborg, T. and Johansen, M. (1988). Timber joints under long-term loading: Splice joints under alternating relative humidity. SBI forlag.

Forsén, H. and Tarvainen, V. (2000). Accuracy and functionality of hand held wood moisture content meters. Technical Research Centre of Finland Espoo, Finland.

Fortino, S., Mirianon, F., and Toratti, T. (2009). “A 3D moisture-stress FEM analysis for time dependent problems in timber structures." Mechanics of Time-Dependent Materials, 13(4), 333356.

Fragiacomo, M. (2005). "A finite element model for long-term analysis of timber-concrete composite beams." Structural Engineering and Mechanics, 20.2, 173-189.

Fragiacomo, M. and Davies, M. (2011). "Long-term behavior of prestressed LVL members. ii: Analytical approach.” Journal of Structural Engineering, 137(12), 1562-1572.

Frandsen, H. L., Damkilde, L., and Svensson, S. (2007). “A revised multi-fickian moisture transport model to describe non-fickian effects in wood." Holzforschung, 61(5), 563-572.

Giorgini, S., Neale, A., Palermo, A., Carradine, D., Pampanin, S., and Buchanan, A. (2010). "Predicting time dependent effects in unbonded post-tensioned timber beams and frames." CIBW18, 1-10.

Granello, G., Giorgini, S., Palermo, A., Carradine, D., Pampanin, S., and Finch, R. (2017). "Longterm behavior of LVL post-tensioned timber beams.” Journal of Structural Engineering In press. 
Granello, G., Palermo, A., and Valipour, H. (2016). "Coupled finite element-finite difference formulation for long-term analysis of unbonded post-tensioned timber beams." Engineering Structures .Under review (2016).

Hanhijarvi, A. (1995). "Modelling of creep deformation mechanisms in wood.” PhD thesis, Helsinki University of Technology.

Hassani, M. M., Wittel, F. K., Hering, S., and Herrmann, H. J. (2015). "Rheological model for wood." Computer Methods in Applied Mechanics and Engineering, 283, 1032-1060.

Khorsandnia, N., Schänzlin, J., Valipour, H., and Crews, K. (2015). “Coupled finite elementfinite difference formulation for long-term analysis of timber-concrete composite structures." Engineering Structures, 96, 139-152.

Kingston, R. and Clarke, L. (1961). "Some aspects of the rheological behaviour of wood." Australian Journal of Applied Science, 12(2), 227-240.

Krabbenhoft, K. and Damkilde, L. (2004). "A model for non-fickian moisture transfer in wood." Materials and structures, 37(9), 615-622.

Krackler, V., Keunecke, D., Niemz, P., and Hurst, A. (2011). "Possible fields of hardwood application.” WOOD RESEARCH, 56(1), 125-136.

Leicester, R. (2001). "Engineered durability for timber construction.” Progress in Structural Engineering and Materials, 3(3), 216-227.

Leyder, C., Chatzi, E., and Frangi, A. (2015a). "Structural Health Monitoring of an Innovative Timber Building." Second International Conference on Performance-based and Life-cycle Structural Engineering - The University of Queensland, Australia, 1383-1392.

Leyder, C., Wanninger, F., Frangi, A., and Chatzi, E. (2015b). "Dynamic response of an innovative hybrid structure in hardwood." Proceedings of the Institution of Civil Engineers-Construction Materials, 168(3), 132-143.

Lu, J. and Leicester, R. (1997). "Mechano-sorptive effects on timber creep." Wood science and technology, 31(5), 331-335.

Mårtensson, A. (1994). "Creep behavior of structural timber under varying humidity conditions.” 
Journal of Structural Engineering, 120(9), 2565-2582.

Morlier, P. (2004). Creep in timber structures, Vol. 8. CRC Press.

Naaman, A. E. (1982). Prestressed concrete analysis and design: fundamentals. McGraw-Hill New York.

Palermo, A., Pampanin, S., Buchanan, A., and Newcombe, M. (2005). "Seismic design of multistorey buildings using laminated veneer lumber (lvl)." New Zealand Society for Earthquake Engineering Conference, Wairakei, New Zealand.

Palka, L. (1973). "Predicting the effect of specific gravity, moisture content, temperature and strain rate on the elastic properties of softwoods." Wood Science and Technology, 7(2), 127-141.

Priestley, N. M. J. (1991). “Overview of the presss research program.” PCI Journal, 36(4), 50-57.

Ranta-Maunus, A. (1975). “The viscoelasticity of wood at varying moisture content.” Wood Science and Technology, 9, 189-205.

Rasmussen, E. F. (1961). Dry Kiln: Operator's Manual. Number 188. US Department of Agriculture.

Sarti, F., Palermo, A., Pampanin, S., and Berman, J. (2017). "Determination of the seismic performance factors for post-tensioned rocking timber wall systems." Earthquake Engineering \& Structural Dynamics, 46(2), 181-200.

Schaffer, E. L. (1972). "Modelling the creep of wood in a changing moisture environment..” Wood and Fiber, 3.

Schänzlin, J. (2010). "Modeling the long-term behavior of structural timber for typical service class-ii-conditions in South-West Germany." Habilitation, University of Stuttgart.

SIA260 (2013). “260: Grundlagen der Projektierung von Tragwerken [Basic design principles].” Schweizerischer Ingenieur-und Architekten-Verein, Zürich In German.

SIA265 (2012). “265: Holzbau [Timber Engineering].” Schweizerischer Ingenieur-und Architektenverein, Zürich In German.

Stahlton AG. "Vorspanntechnik [Post-tensioning technolgy] http://www.stahlton.ch, In German. Svensson, S. and Toratti, T. (2002). "Mechanical response of wood perpendicular to grain when 
subjected to changes of humidity." Wood Science and Technology, 36(2), 145-156.

Taucer, F., Spacone, E., and Filippou, F. C. (1991). A fiber beam-column element for seismic response analysis of reinforced concrete structures, Vol. 91. Earthquake Engineering Research Center, College of Engineering, University of California Berkekey, California.

Toratti, T. (1992). “Creep of timber beams in variable environment.” PhD thesis, Helsinki University of Technology.

van Beerschoten, W. A., Palermo, A., and Carradine, D. (2012). "Gravity design of post-tensioned timber frames for multi-storey buildings.” Structures Congress 2012, 1733-1744.

Van de Kuilen, J.-W. (2007). "Service life modelling of timber structures.” Materials and Structures, 40(1), 151-161.

Wadsö, L. (1994). “Describing non-fickian water-vapour sorption in wood.” Journal of Materials Science, 29(9), 2367-2372.

Wanninger, F. (2015). “Post-tensioned timber frame structures.” Ph.D. thesis, Eidgenössische Technische Hochschule ETH Zürich, Nr. 22815.

Wanninger, F., Frangi, A., and Fragiacomo, M. (2014). "Long-Term Behavior of Posttensioned Timber Connections.” Journal of Structural Engineering, 141(6), 04014155. 


\section{APPENDIX: CALIBRATION OF THE NUMERICAL MODEL}

\section{Model Calibration}

The model calibration was performed on experimental data, obtained from tests carried out by Wanninger et al. 2014. A post-tensioned beam and a post-tensioned beam-column specimen were monitored for 4 years in the laboratory at ETH Zürich (cf. figure 14).

The columns are made of ash glulam and the beams are mostly made of spruce glulam. The two lamellae at the bottom of the beams are made of ash; however, since this portion is small, the entire element were modelled as spruce. The columns are 750mm high and the beams are $1 \mathrm{~m}$ long. Both elements present a section of $120 \mathrm{~mm}$ x $240 \mathrm{~mm}$. Details on the geometry are reported in figure 15 .

\section{Modelling of the Moisture Content - Diffusion Analysis}

As the moisture content of both the column and beam from the post-tensioned joint (figure 14) was monitored along with the climate conditions, this test was implemented to calibrate the parameters $S$ and $D_{0}$ for the diffusion analysis. The specimens were placed in the laboratory at ETH Zürich (figure 14). Temperature and relative humidity are reported in figure 16 (Wanninger et al. 2014). The temperature was almost constant at around 22 to $23^{\circ} \mathrm{C}$ while the relative humidity seasonally varied between $40 \%$ and $60 \%$.

The moisture contents in the beam (spruce) and the column (ash) were measured by the electrical resistance method for a duration of approximately 2 years. Two measurement points were located in the beam, one at $30 \mathrm{~mm}$ and one at $60 \mathrm{~mm}$ depth. A single measurement point was located on the column at a depth of $30 \mathrm{~mm}$. The average moisture content within the timber sections was simulated by considering the environmental conditions and is reported in figure 16. A time step equal to 6 hours was set, as recommended by several authors (e.g. (Schänzlin 2010)). Assuming an initial moisture content equal to $9 \%$, the best fit was obtained for $S=8.310^{-8} \mathrm{~m} / \mathrm{s}$ and $D_{0}=1.72 * 10^{-10} \mathrm{~m}^{2} / \mathrm{s}$ for both ash and spruce. These numbers are compatible with the values proposed for New Zealand Laminated Veneer Lumber (Granello et al. 2016). A comparison between the experimental and numerical results is reported in figure 17.

The model is able to simulate the moisture content trend reasonably well; however, a systematic 
error of about $0.5-1 \%$ between the experimental and numerical values is present. This error can be accredited to several causes, for example:

- the moisture content measurements were taken at specific points while the model considers the average moisture content within the section. This might lead to a systematic shift in the data.

- the instrument implemented to measure the moisture content has limited accuracy (Forsén and Tarvainen 2000).

- the diffusion process was simulated in a simplified way by considering $2 \mathrm{D}$ diffusion. Results might be improved by utilizing more advanced models.

Nevertheless, the accuracy obtained in terms of moisture content is considered sufficient for the purpose of the general model, i.e., estimating the post-tensioning loss over time.

Numerical model for timber loaded parallel to the grain (post-tensioned beam)

The post-tensioned beam specimen was initially post-tensioned to $79 \mathrm{kN}$ with a single tendon (cross-section area $A_{s}=133 \mathrm{~mm}^{2}$ ). The elastic modulus of steel $E_{s}$ was considered equal to $197 \mathrm{GPa}$ with a thermal expansion coefficient of $\alpha_{s}=10^{-5}$, whereas the elastic modulus of timber $E$ was set equal to $11 \mathrm{GPa}$ (spruce wood, properties from (Wanninger et al. 2014)). The model was calibrated for the following material parameters (for a detailed explanation of the parameters the reader may refer to Toratti 1992):

- Pure creep: $\tau_{n}=[0.1,1,10,100,1000,10000]$

$$
J_{n}=[0.0080,-0.0617,0.1845,-0.0375,0.1233,-0.0073]
$$

- mechano-sorptive creep: $c=0.5$ and $J^{\infty}=0.9$;

- shrinkage-swelling: $\alpha_{u, p a r}=0.00625$ and $b=1.3$;

The irrecoverable contribution of the mechano-sorptive strain is often neglected when timber is loaded parallel to grain (e.g.Toratti 1992; Granello et al. 2016) and will therefore be omitted in this model. The remaining model parameters, namely $u_{r e f}$ and $k_{u}$ were set equal to 0.2 and 1.06 , 
according to Toratti 1992. Again, a time step of 6 hours was utilized for the analysis.

By considering the environmental conditions in the room (figure 16) and the diffusion analysis parameters, as presented previously, the post-tensioning trend obtained is presented in figure 18 (experimental data from (Wanninger et al. 2014)).

The model describes the post-tensioning trend over time with reasonable accuracy.

Numerical model for timber loaded parallel and perpendicular to the grain (post-tensioned beamcolumn joint)

The post-tensioned beam-column joint was initially tensioned to $86 \mathrm{kN}$. The elastic modulus of ash perpendicular to the grain $E_{90, \text { mean }}$ was set equal to $860 \mathrm{MPa}$ (Wanninger et al. 2014). The material parameters for ash perpendicular to the grain (see (Toratti 1992)) were calibrated as follows:

- Pure creep: $\tau_{n}=[0.1,1,10,100,1000,10000]$

$$
J_{n}=[-0.0220,0.0797,0.0834,0.1640,0.0828,1.0086]
$$

- mechano-sorptive creep: $c=1, J^{\infty}=0.6$ and $m_{m s}=0.005$;

- shrinkage-swelling: $\alpha_{u, p e r p}=0.2$ and $b=1.3$;

The environmental conditions considered are the same as those reported in figure 16 . The simulated post-tensioning trend is reported in figure 19 (experimental data from (Wanninger et al. 2014)). The proposed model describes the experimental data with reasonable accuracy. 


\section{List of Tables}

1 Strength and stiffness properties in $[\mathrm{MPa}]$ and density in $\left[\mathrm{kg} / \mathrm{m}^{3}\right]$ for strength grade

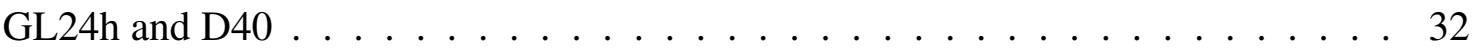

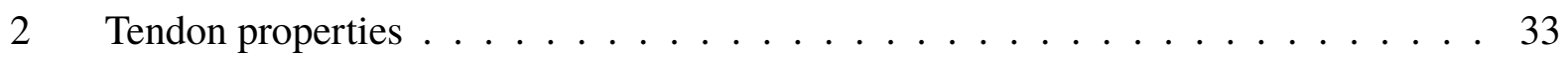

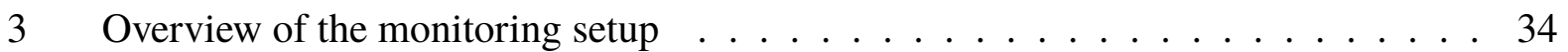

4 Comparison of post-tension losses for the uncontrolled environment in the laboratory and the uncontrolled environment in the HoNR building. (Values for 1 and 2 years: measured. Values for 10 and 50 years: extrapolated.) . . . . . . . . . . 35 
TABLE 1. Strength and stiffness properties in $[\mathrm{MPa}]$ and density in $\left[\mathrm{kg} / \mathrm{m}^{3}\right]$ for strength grade GL24h and D40

\begin{tabular}{llcc}
\hline Property & & \multicolumn{2}{c}{ Strength grade } \\
& & GL24h & D40 \\
\hline Compressive strength parallel to the grain & $f_{c, 0, k}$ & 22 & 26 \\
Compressive strength perpendicular to the grain & $f_{c, 90, k}$ & 3 & 8.3 \\
Modulus of elasticity parallel to the grain & $E_{0, \text { mean }}$ & 11000 & 13000 \\
Modulus of elasticity perpendicular to the grain & $E_{90, \text { mean }}$ & 300 & 860 \\
Shear modulus & $G_{\text {mean }}$ & 500 & 810 \\
\hline Density at 12\% moisture content & $\rho_{k}$ & 380 & 550
\end{tabular}


TABLE 2. Tendon properties

\begin{tabular}{llc}
\hline Property & & Y1770 4-06 \\
\hline Number of strands & $N$ & 4 \\
Cross section area tendon & $A_{p}$ & $600 \mathrm{~mm}^{2}$ \\
Modulus of elasticity tendon & $E_{p}$ & $197000 \mathrm{MPa}$ \\
\hline Tensile strength tendon & $f_{p, k}$ & $1770 \mathrm{MPa}$ \\
Applicable design load tendon & $P_{\max }$ & $850 \mathrm{kN}$ \\
Applied post-tension load tendon & $P_{\max }$ & $700 \mathrm{kN}$ \\
\hline
\end{tabular}




\begin{tabular}{lcc}
\hline Sensor type & Amount & Start of operation \\
\hline Load cells $1^{\text {st }}$ storey & 8 load cells & January 2014 \\
Load cells $2^{\text {nd }}$ storey & 8 load cells & July 2014 \\
Moisture content $1^{\text {st }}$ storey & 21 locations & January 2014 \\
Moisture content $2^{\text {nd }}$ storey & 20 locations & July 2014 \\
T\&RH (construction site) & 1 location & January 2014-January 2015 \\
T\&RH (operation phase) & 12 locations & February 2015 \\
\hline
\end{tabular}

TABLE 3. Overview of the monitoring setup 


\begin{tabular}{lccc}
\hline & Laboratory test & Building C-storey & Building D-storey \\
\hline 1 year & $8.0 \%$ & $3.0 \%$ & $4.1 \%$ \\
2 years & $8.5 \%$ & $7.05 \%$ & $6.7 \%$ \\
10 years & $14 \%$ & - & - \\
50 years & $20 \%$ & - & - \\
\hline
\end{tabular}

TABLE 4. Comparison of post-tension losses for the uncontrolled environment in the laboratory and the uncontrolled environment in the HoNR building. (Values for 1 and 2 years: measured. Values for 10 and 50 years: extrapolated.) 


\section{List of Figures}

1 The House of Natural Resources - pilot building for the implementation of hardwood 38

$2 \quad 1^{\text {st }}$ storey post-tensioned timber frame $(\mathrm{HoNR}) \ldots \ldots \ldots$

3 Pictures of implemented sensors . . . . . . . . . . . . . . . . . 40

4 Sensor positions C and D storey (green triangles (LC): position of load cells, blue circles (M): moisture measurement points, pink squares (TRH): temperature and relative humidity sensors, Climate station: position during the construction phase) . 41

5 Climate inside the building (transition and operation phase: grey: measured values, black: mean value) ....................... 42

6 Moisture content of the timber frame - at different locations and mean value (black

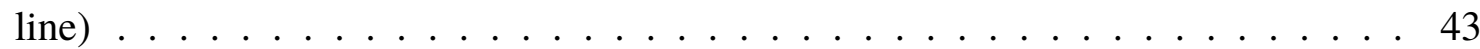

7 Comparison of post-tension losses in the HoNR (black lines) and post-tension losses in the laboratory (grey lines). The time scale corresponds to the HoNR data; the laboratory data has been shifted in time to match the day of post-tensioning. The vertical line at the beginning of the data corresponds to the post-tensioning

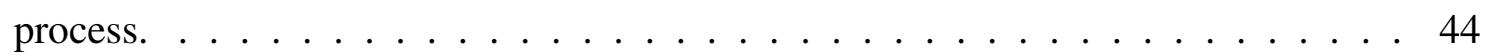

8 Flowchart of the numerical model . . . . . . . . . . . . . . . . . 45

9 Humidity flux between the element and the environment. . . . . . . . . . . . 46

10 Moisture content measurements in the columns and beams on the D-storey (grey values); simulation (black dotted line); average of experimental data (black continuous line $) \ldots \ldots \ldots \ldots \ldots \ldots$

11 Moisture content measurements in the columns and beams on the C-storey (grey values); simulation (black dotted line); average of experimental data (black continusous line). . . . . . . . . . . . . . . . . . . . . . 48

12 Post-tensioning trend: left figure: C-storey, right figure: D-story. Dotted black line: simulation results; continuous black line: average of experimental data; grey lines: experimental data. . . . . . . . . . . . . . . . . . 
13 Contributions to the overall post-tensioning loss of different factors: columns (dashed black line); beams (continuous thick black line); thermal strains in the post-tensioning cable (continuous thin black line); total loss (grey line). . . . . . . 50

14 Creep tests on spruce and ash blocks (controlled environment) and on posttensioned beam and joint specimens (uncontrolled environment) . . . . . . . . 51

15 Geometrical properties of the specimens utilized to calibrate the model . . . . . . 52

16 Measured Relative humidity $(\mathrm{RH})$ and Temperature $(\mathrm{T})$ in the laboratory (extended

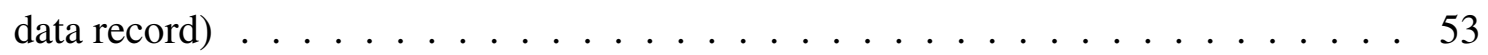

17 Moisture content (MC): simulation vs experimental data for the column and beam

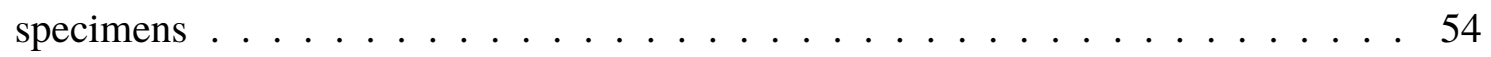

18 Post-tensioning trend of the beam: measured data vs simulation. . . . . . . . . 55

19 Post-tensioning trend of the beam-column joint: measured data vs simulation. . . . 56 


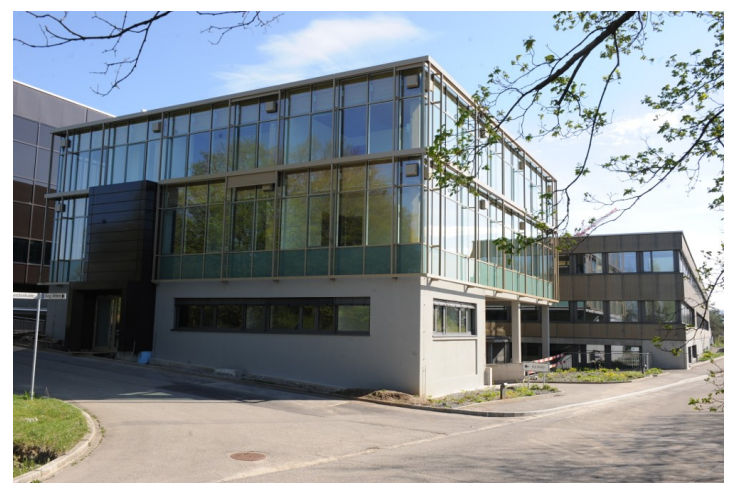

Fig. 1. The House of Natural Resources - pilot building for the implementation of hardwood 


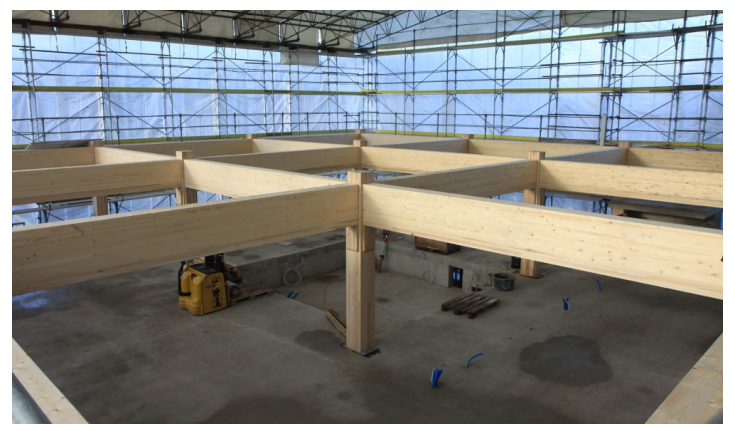

Fig. 2. $1^{\text {st }}$ storey post-tensioned timber frame (HoNR) 


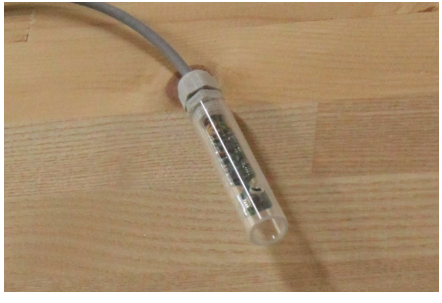

(a) $\mathrm{T} \& \mathrm{RH}$ sensor

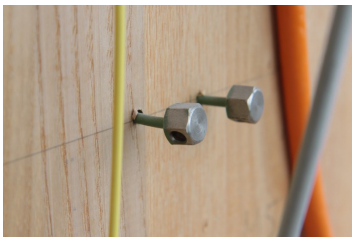

(b) Moisture electrodes

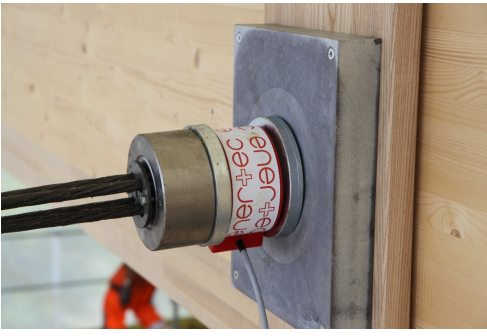

(c) Load cell

Fig. 3. Pictures of implemented sensors 


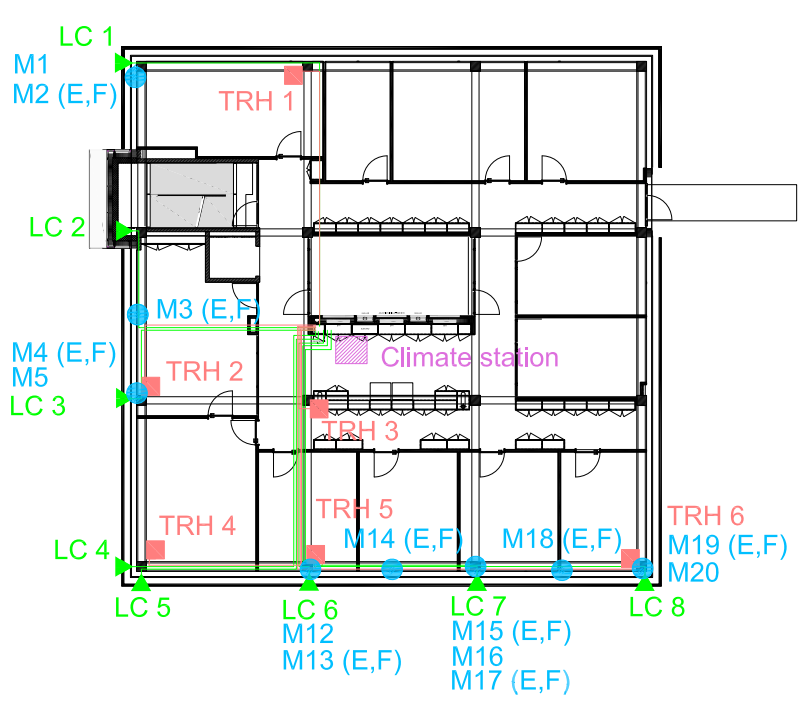

(a) Sensor positions - C-storey

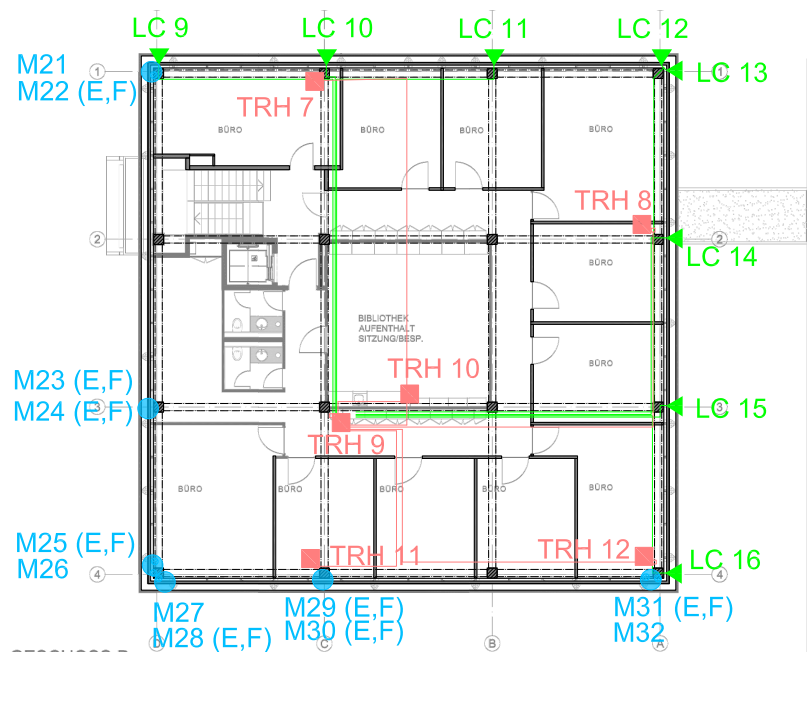

(b) Sensor positions - D-storey

Fig. 4. Sensor positions C and D storey (green triangles (LC): position of load cells, blue circles $(\mathrm{M})$ : moisture measurement points, pink squares (TRH): temperature and relative humidity sensors, Climate station: position during the construction phase) 


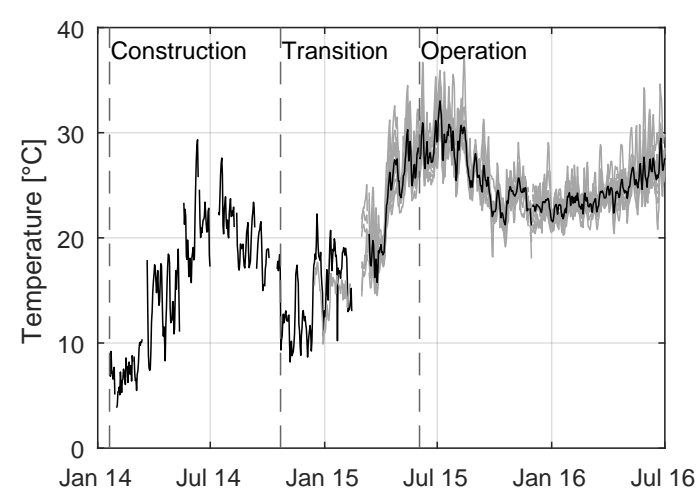

(a) Temperatures

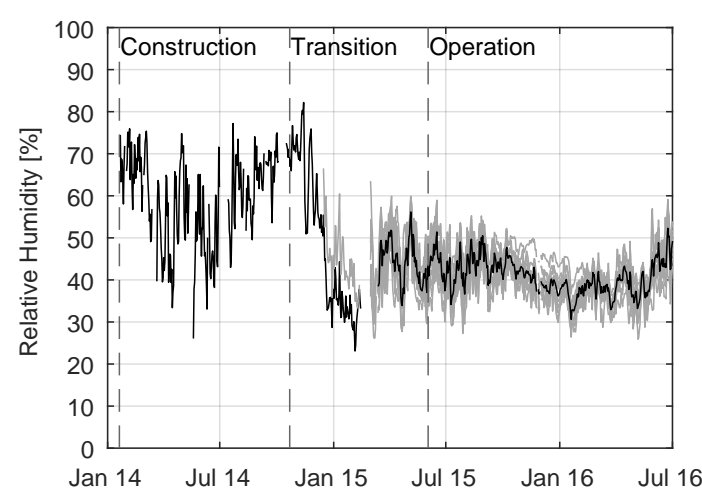

(b) Relative humidity

Fig. 5. Climate inside the building (transition and operation phase: grey: measured values, black: mean value) 


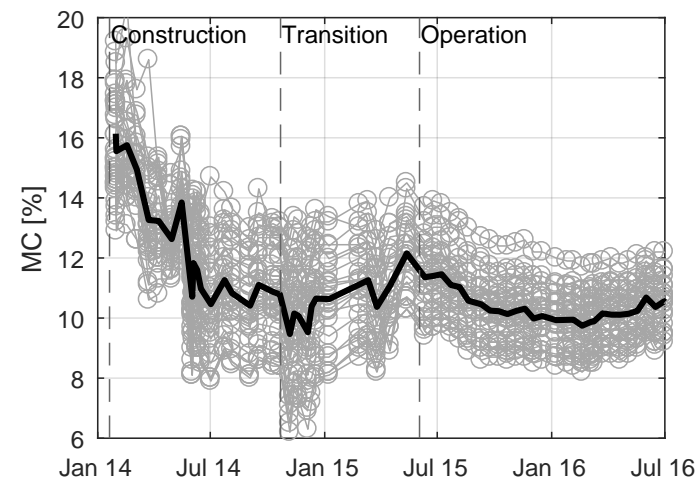

(a) C-storey

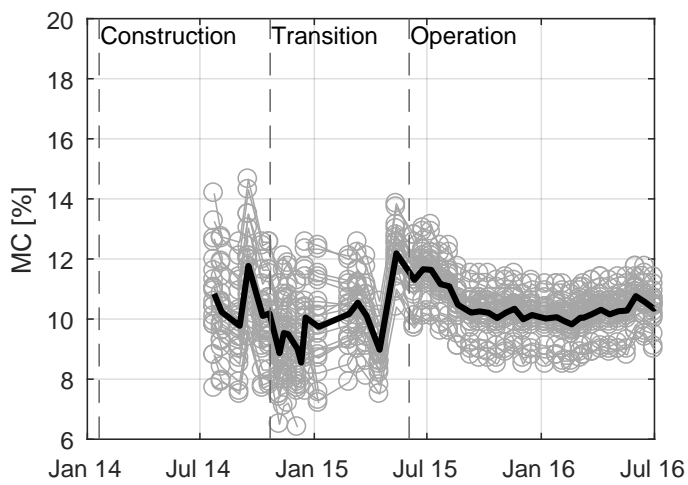

(b) D-storey

Fig. 6. Moisture content of the timber frame - at different locations and mean value (black line) 


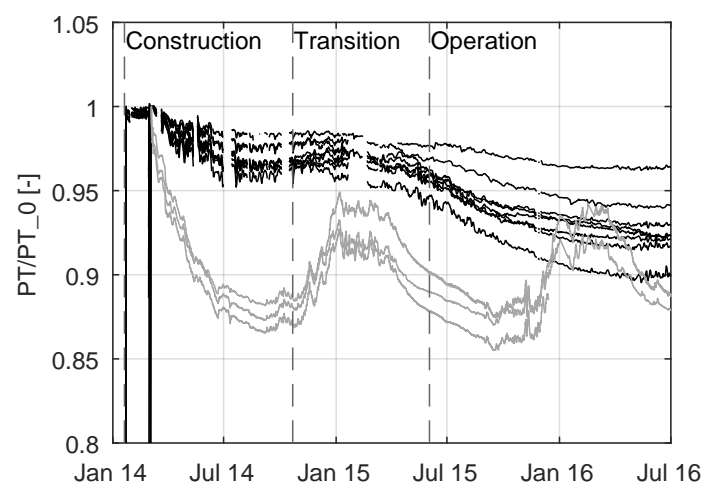

(a) C-storey

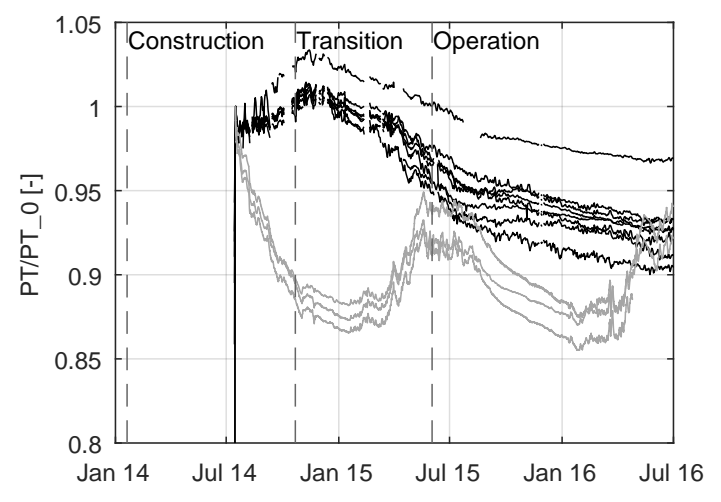

(b) D-storey

Fig. 7. Comparison of post-tension losses in the HoNR (black lines) and post-tension losses in the laboratory (grey lines). The time scale corresponds to the HoNR data; the laboratory data has been shifted in time to match the day of post-tensioning. The vertical line at the beginning of the data corresponds to the post-tensioning process. 
1: Problem Definition

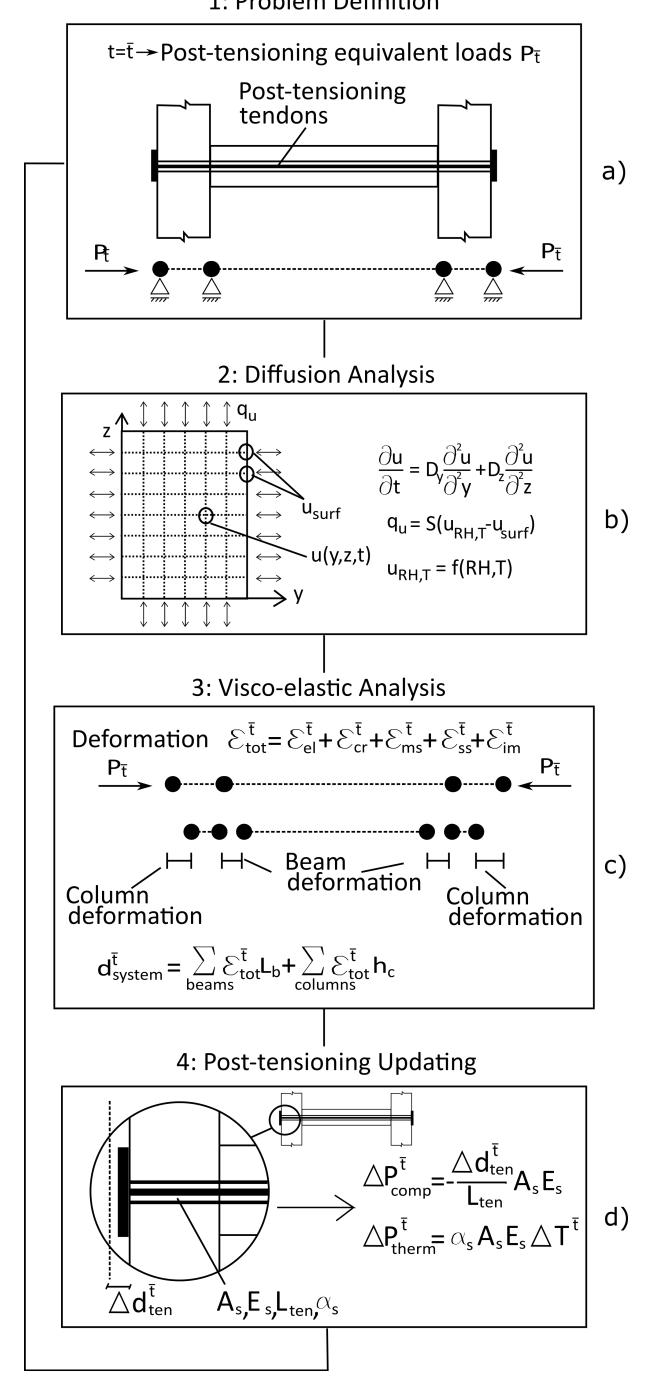

Fig. 8. Flowchart of the numerical model 


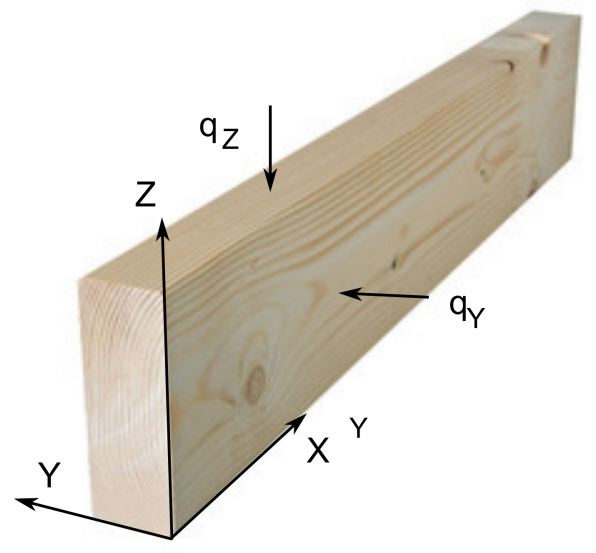

Fig. 9. Humidity flux between the element and the environment. 


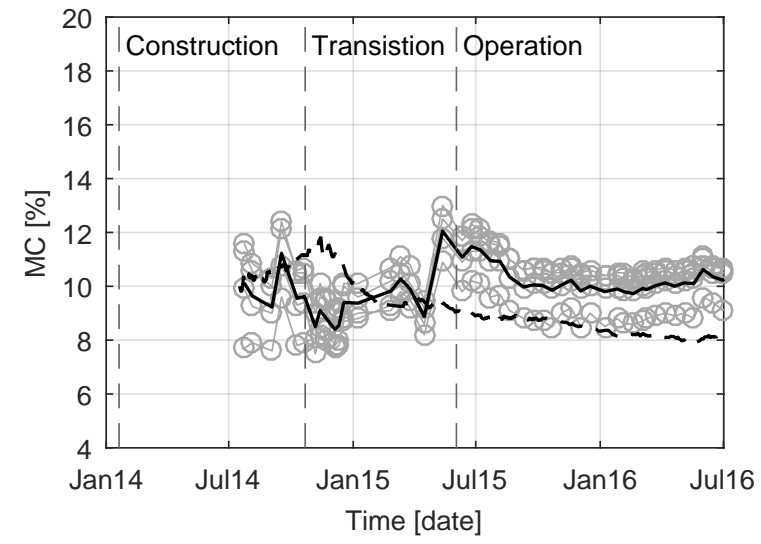

(a) Moisture content in the columns

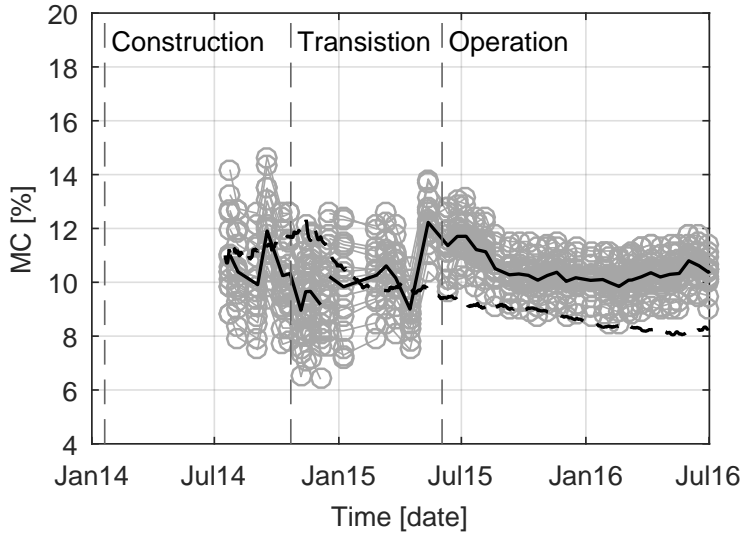

(b) Moisture content in the beams

Fig. 10. Moisture content measurements in the columns and beams on the D-storey (grey values); simulation (black dotted line); average of experimental data (black continuous line). 


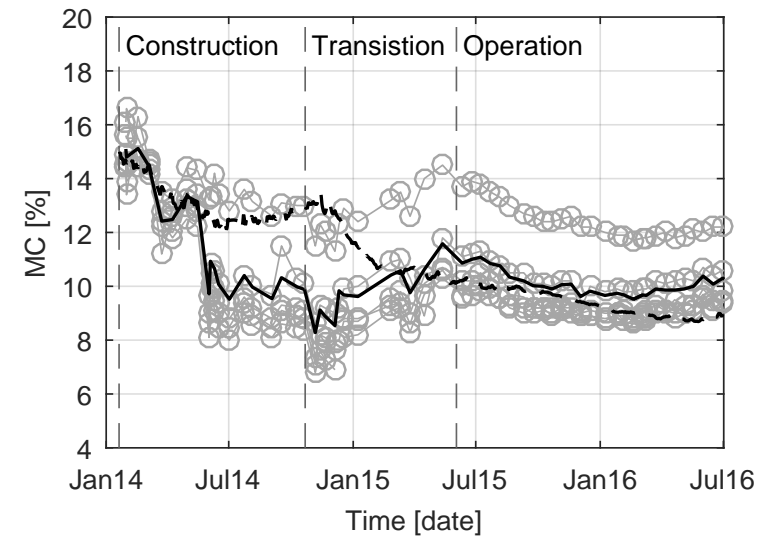

(a) Moisture content in the columns

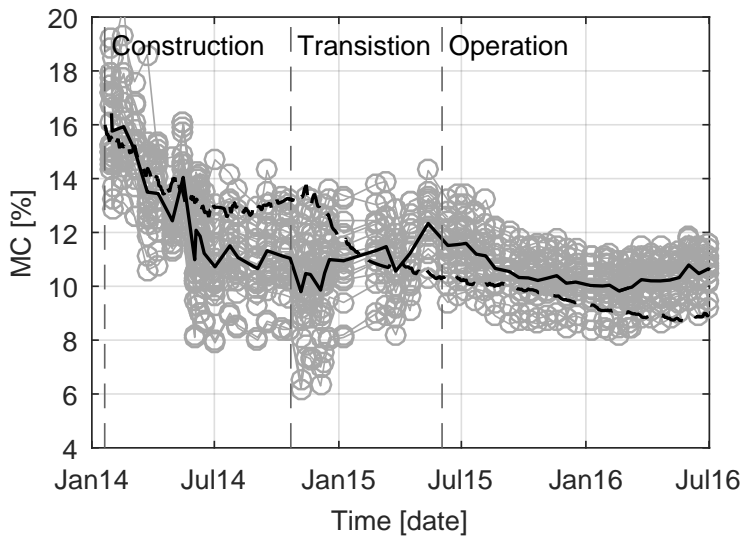

(b) Moisture content in the beams

Fig. 11. Moisture content measurements in the columns and beams on the C-storey (grey values); simulation (black dotted line); average of experimental data (black continusous line). 


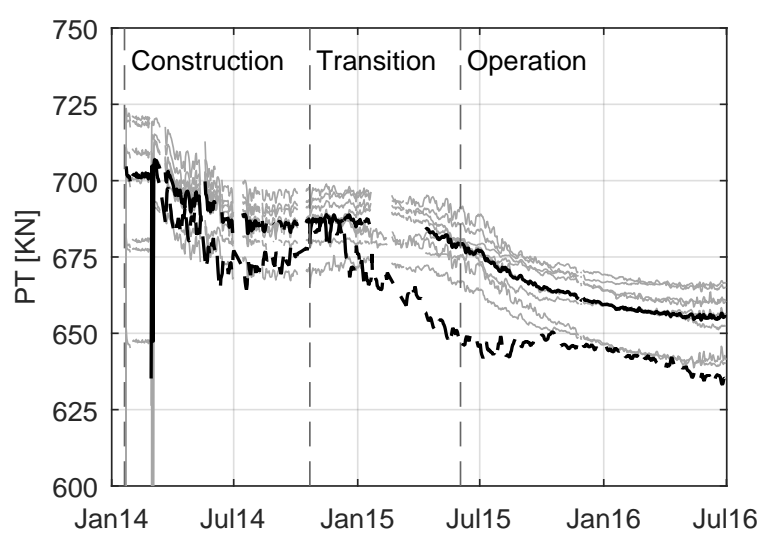

(a) C-storey.

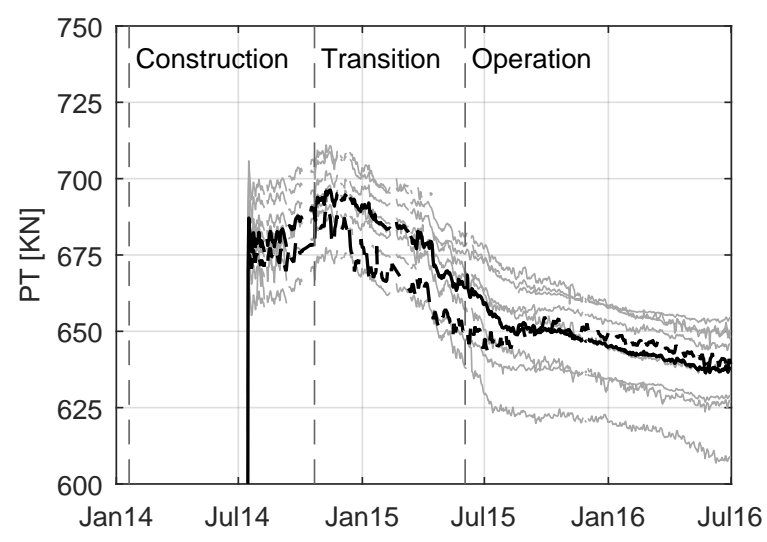

(b) D-storey.

Fig. 12. Post-tensioning trend: left figure: C-storey, right figure: D-story. Dotted black line: simulation results; continuous black line: average of experimental data; grey lines: experimental data. 


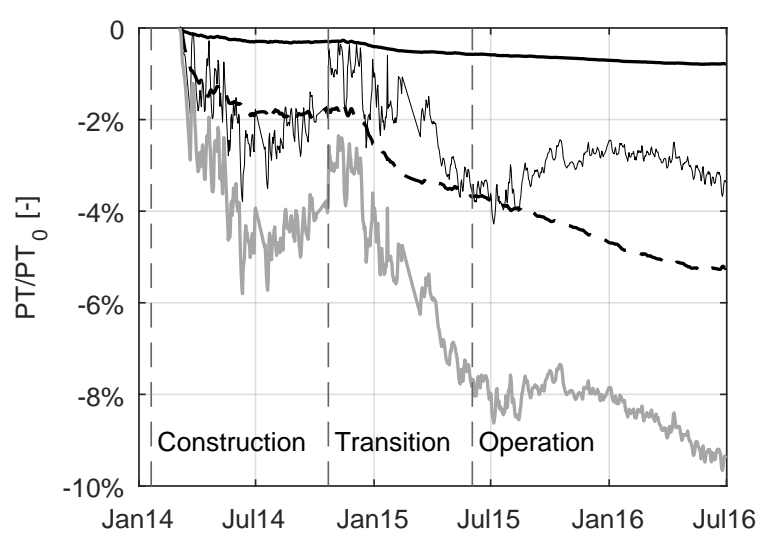

(a) C-storey

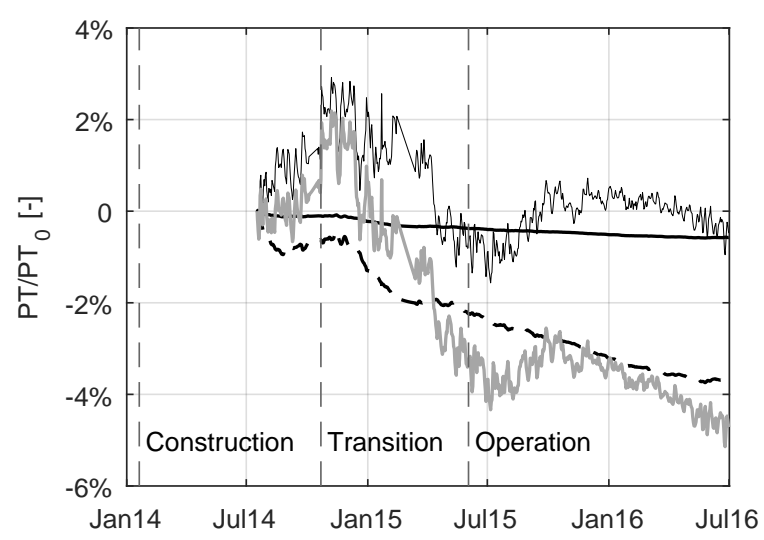

(b) D-storey

Fig. 13. Contributions to the overall post-tensioning loss of different factors: columns (dashed black line); beams (continuous thick black line); thermal strains in the post-tensioning cable (continuous thin black line); total loss (grey line). 

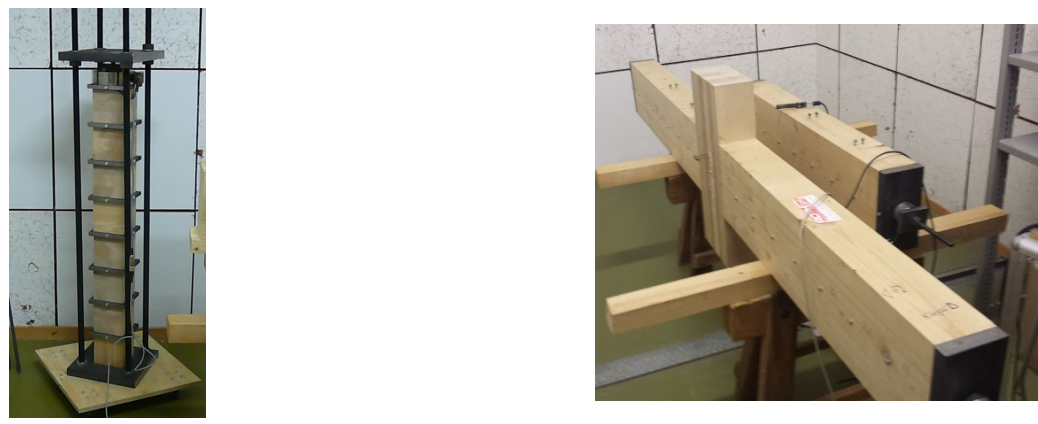

(a) Creep test.

(b) Post-tensioned specimens.

Fig. 14. Creep tests on spruce and ash blocks (controlled environment) and on post-tensioned beam and joint specimens (uncontrolled environment) 


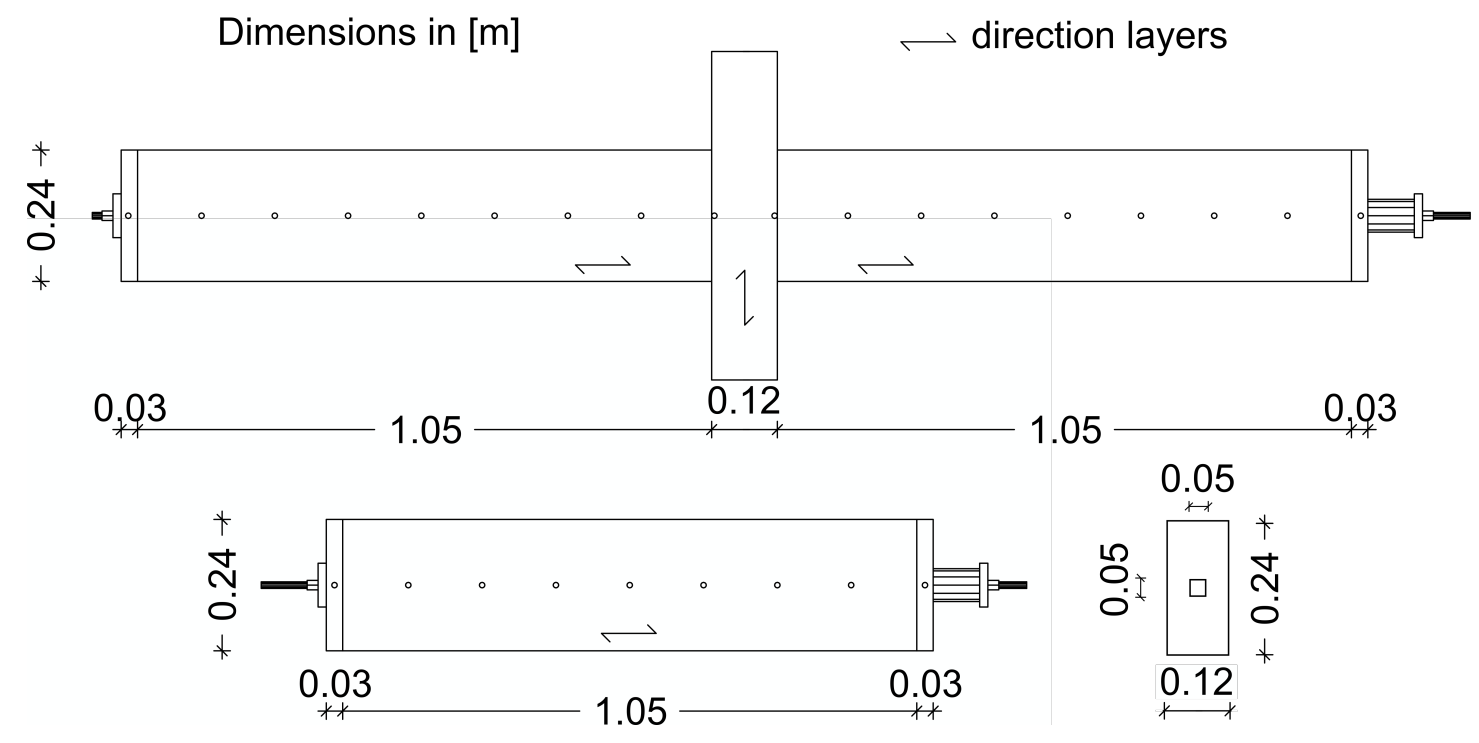

Fig. 15. Geometrical properties of the specimens utilized to calibrate the model 


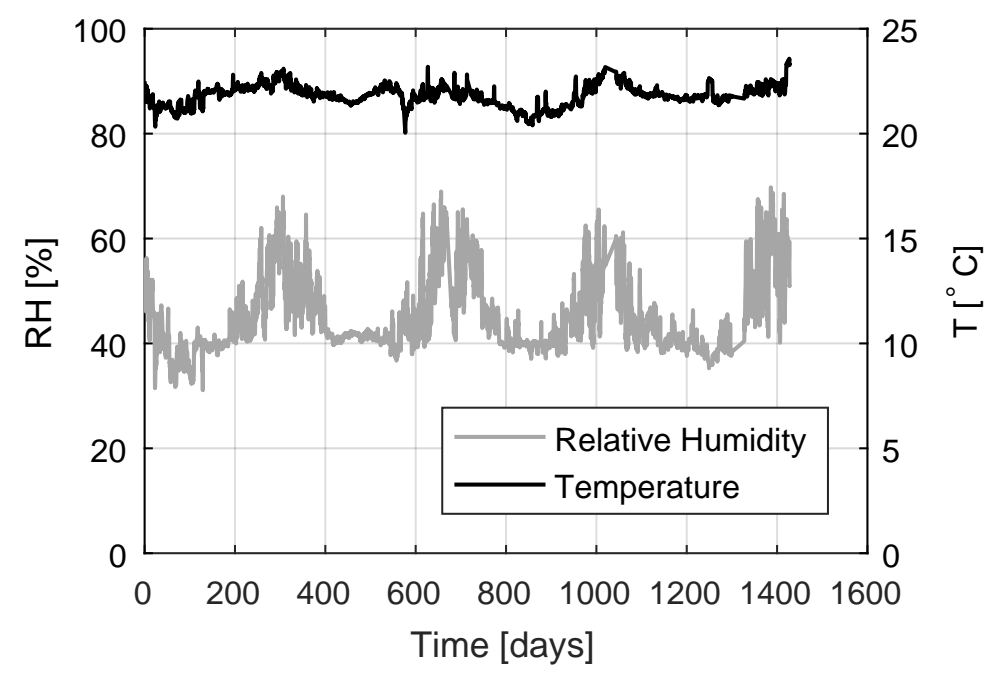

Fig. 16. Measured Relative humidity (RH) and Temperature (T) in the laboratory (extended data record) 


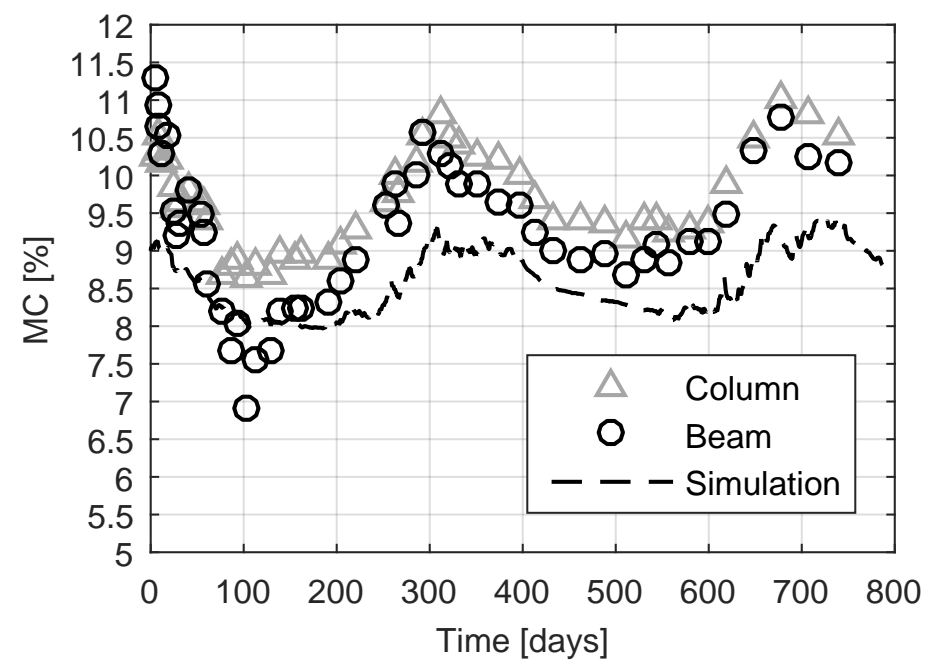

Fig. 17. Moisture content (MC): simulation vs experimental data for the column and beam specimens 


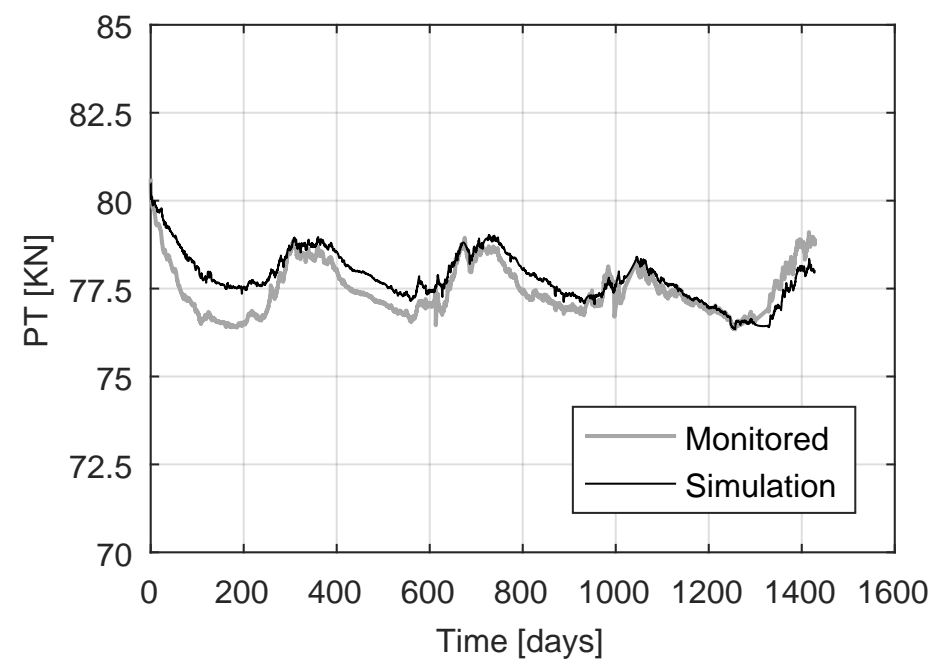

Fig. 18. Post-tensioning trend of the beam: measured data vs simulation. 


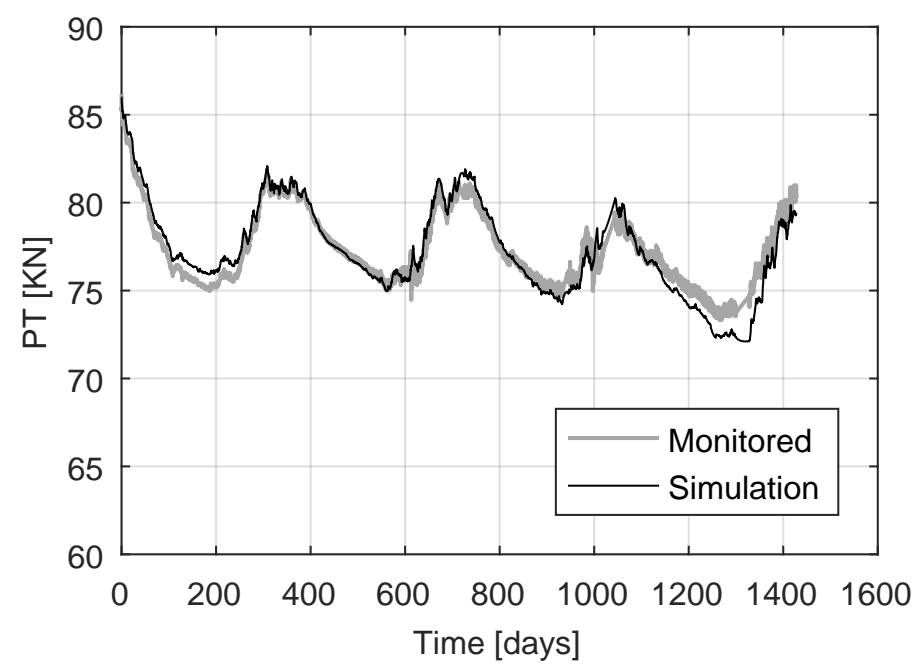

Fig. 19. Post-tensioning trend of the beam-column joint: measured data vs simulation. 